\title{
A Review of Dangerous Dust in Fusion Reactors: from Its Creation to Its Resuspension in Case of LOCA and LOVA
}

\author{
Andrea Malizia *, Luigi Antonio Poggi, Jean-François Ciparisse, Riccardo Rossi, Carlo Bellecci \\ and Pasquale Gaudio
}

Department of Industrial Engineering, Associazione EUROFUSION-ENEA, University of Rome Tor Vergata, Via del Politecnico 1, 00133 Rome, Italy; poggi@ing.uniroma2.it (L.A.P.); jf.ciparisse@gmail.com (J.-F.C.); riccardo.rossi.en@gmail.com (R.R.); bellecci@uniroma2.it (C.B.); gaudio@ing.uniroma2.it (P.G.)

* Correspondence: malizia@ing.uniroma2.it; Tel.: +39-06-7259-7202

Academic Editor: Matthew Hole

Received: 22 April 2016; Accepted: 27 June 2016; Published: 25 July 2016

\begin{abstract}
The choice of materials for the future nuclear fusion reactors is a crucial issue. In the fusion reactors, the combination of very high temperatures, high radiation levels, intense production of transmuting elements and high thermomechanical loads requires very high-performance materials. Erosion of PFCs (Plasma Facing Components) determines their lifetime and generates a source of impurities (i.e., in-vessel tritium and dust inventories), which cool down and dilute the plasma. The resuspension of dust could be a consequences of LOss of Coolant Accidents (LOCA) and LOss of Vacuum Accidents (LOVA) and it can be dangerous because of dust radioactivity, toxicity, and capable of causing an explosion. These characteristics can jeopardize the plant safety and pose a serious threat to the operators. The purpose of this work is to determine the experimental and numerical steeps to develop a numerical model to predict the dust resuspension consequences in case of accidents through a comparison between the experimental results taken from campaigns carried out with STARDUST-U and the numerical simulation developed with CFD codes. The authors in this work will analyze the candidate materials for the future nuclear plants and the consequences of the resuspension of its dust in case of accidents through the experience with STARDUST-U.
\end{abstract}

Keywords: nuclear fusion; security; dust

\section{Introduction}

"Fusion energy holds promise for obtaining the consent of the public, as it can provide intrinsic safety, favorable environmental characteristics and it can address global climate change concerns. In particular, fusion energy has the potential to become a $\mathrm{CO}_{2}$-free clean and inexhaustible energy source. In the world, all nuclear power plants in operation are related to fission, which is based on the fractionation of large atomic nuclei, especially the very heavy elements uranium and plutonium. However, to release energy, an alternative approach is that of nuclear fusion. Unlike fission, nuclei of light atoms gather to create atoms of a more stable and heavy form" [1]. "Fusion is the process which powers the sun and other stars" [2]. "During the fusion of elements with low atomic numbers substantial amounts of energy are released. In the core of the sun, the huge gravitational pressure allows this to happen at temperatures of around 10 million degrees Celsius. Gas raised to these temperatures becomes a "plasma", where the electrons are completely separated from the atomic nuclei (ions)" [2]. "The plasma is a globally neutral ionized gas, consisting of a set of electrons and positive ions. As such, the plasma is considered as the fourth state of matter, which therefore differs from the solid, the liquid and the gaseous." "The most promising combination for power on Earth today is the fusion of a deuterium atom with a tritium one. The process, which requires temperatures of approximately 72 million degrees $F$ (39 million degrees (elsius), produces 17.6 million electron volts of energy [3]." 
Nowadays the experimental nuclear facilities present worldwide are based on the deuterium-tritium technological concept. Deuterium and tritium are 2 isotopes of hydrogen, the first one can be obtained through an extraction process starting from the sea water, the second one can be obtained using lithium panel. Lithium is present in the sea rocks so it is clear that the combustible necessary to let this plant work is almost unlimited. The security levels of these plants are quite high because, in case of a malfunction, there are plasma material interaction that provokes an immediate reduction of temperature of the plasma causing its turn off. The products coming from chemical combustion are negligible as the radioactivity levels inside the facilities. Actually this is a promising alternative for the production of electricity with a reduced $\mathrm{CO}_{2}$ and other gas emission, the main problem that has to be faced is obtain a continuous production of electric energy. The International Thermonuclear Experimental Reactor (ITER, see Figure 1) main goal is be the first nuclear fusion plant with a positive energetic efficiency.

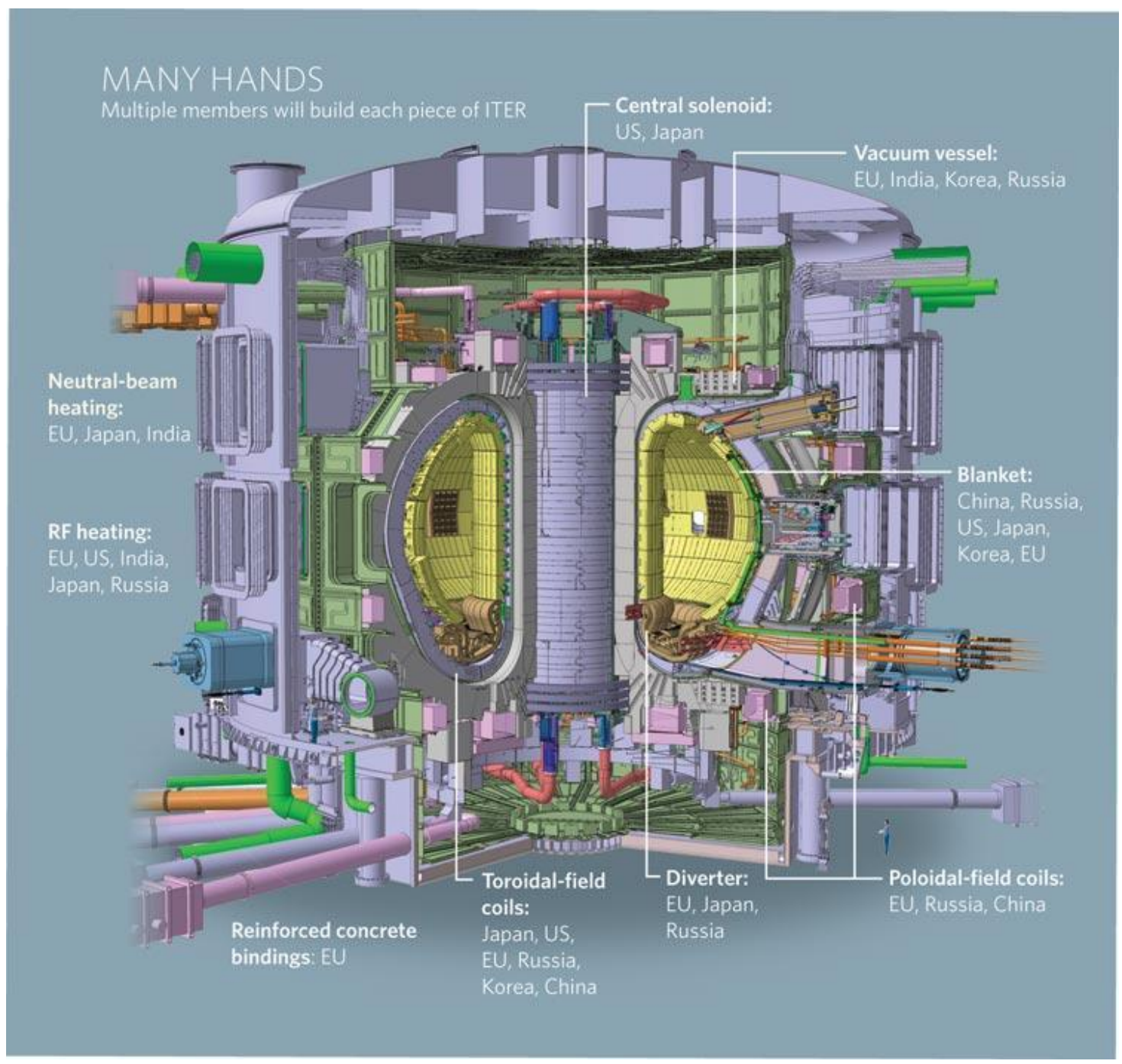

Figure 1. ITER scheme. This figure is taken from [4].

There are safety and security concerns related to several technological peculiarities of these plants, one of the most important is the creation of dust due to the plasma material interaction inside the vacuum vessel (VV) of the nuclear fusion plants [5-12] and its resuspension due to accidents like Loss of Vacuum (LOVA), Loss of Coolant (LOCA) [13,14]. 


\section{Dust in Fusion Nuclear Reactors}

"The combination of high temperatures, high radiation damage levels, intense production of transmuting elements (in particular, $\mathrm{H}$ and $\mathrm{He}$ ) and high thermomechanical loads that produce significant primary and secondary stresses and time-dependent strains requires very high-performance materials for fusion energy systems" [15]. The materials that have direct interaction with the plasma must resist to load of energy till $14 \mathrm{MeV}$ due to the neutrons. These neutrons can produce displacements and transmutation that can provokes material defects and gas atoms (like $\mathrm{He}$ or $\mathrm{H}$ ). The plasma interaction temperatures are in the range of 780-3500 K causing several erosion phenomena. "The selection of plasma facing materials is mainly limited by their capability of absorbing heat and minimizing plasma contamination" [16-18].

\subsection{Materials based on carbon}

International Thermonuclear Experimental Reactor (ITER) and DEMO, the future nuclear fusion plants that will be build, will be characterized by PMIs (Plasma Material Interactions) but, actually, is it not possible estimate the exact numbers of these events [19-22].

Since few years ago graphite was used as PFC because of the following characteristics $[18,23]$ :

(1) "A good compatibility with a wide variety of plasma operation conditions."

(2) "A good thermo-mechanical properties of carbon fiber composites (CFC) and the lack of melting under transient power fluxes makes these materials compatible with high power flux plasmas."

(3) "A high density plasmas in ITER-like regimes were obtained in the experiments with a relatively low core contamination $\left(\mathrm{Z}_{\text {eff }}=1.5-2.0\right)$."

(4) "Due to its Low-Z, the core radiative losses associated with $C$ in high temperature plasmas are low, while the divertor radiative losses by $C$, which are necessary to maintain semi-detached operation in ITER, can decrease the divertor power flux by more than a factor of $\sim 2$ compared with fully attached conditions."

The main negative aspect in using carbon material were [24-26]:

(1) High erosion trend.

(2) High tritium retention levels

During these year have been constructed database in order to analyze "yield data with respect to ion energy, target temperature and ion flux".

"The database suggests a weak dependence of the erosion yield on ion impact energy between 10 and $200 \mathrm{eV}$ and a clear tendency for the yield to decrease with increasing flux density [27], implying a 2.5-fold reduction in yield for the ITER strike-point conditions compared with previous assumptions $(\sim 1 \%)^{\prime \prime}$.

"Figure 2 taken from [18]" shows the variation of gross erosion expected in ITER versus the distance along outer target from separatrix.

"This figure illustrates the complex coupling of target erosion and power load and associated tritium retention which makes predictions to ITER uncertain. [18]

(a) The carbon chemical erosion yield depends strongly on the target temperature, which is determined by the incident plasma power flux.

(b) The power flux at the divertor is determined by the radiative losses and the degree of detachment, which is strongly influenced by the release of carbon into the divertor by chemical erosion. [18]"

The different projects and test actually leave uncertainties about the plasma conditions in ITER that are strongly related to the variation of event like Edge Localizated Modes (ELMs) or disruption that strongly contribute to sputtering and erosion phenomena's. [18]

For these reasons, actually, the Carbon is not considered as material for ITER. 


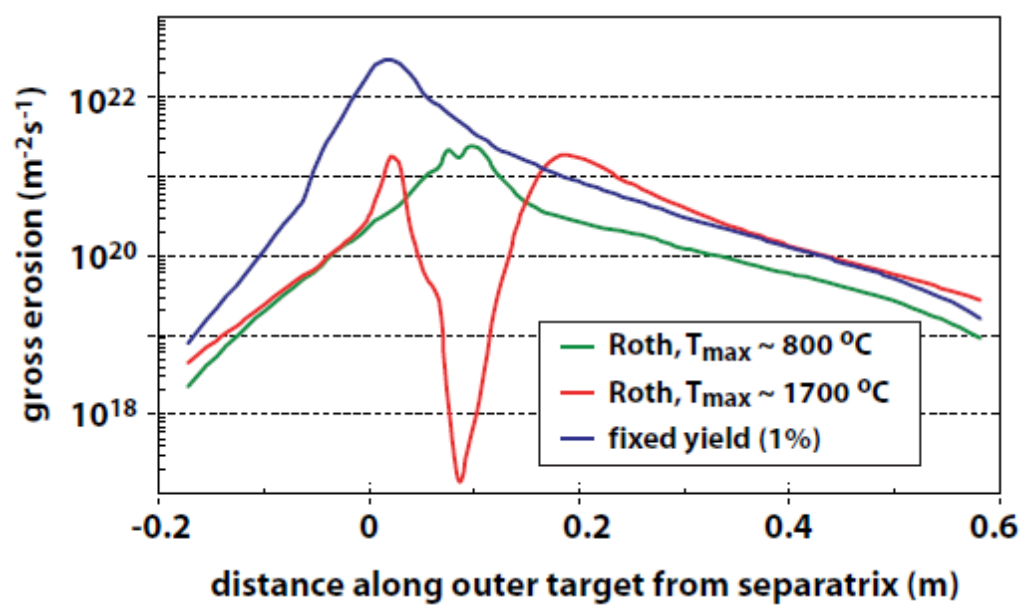

Figure 2. "Calculated chemical gross erosion of the outer ITER divertor target assuming a fixed erosion yield of $1 \%$ or the full erosion dependence on energy, surface temperature and particle flux. Calculations are done for a high and a low surface temperature case". This figure is taken from [18].

\subsection{Material Based on Beryllium}

"Use of beryllium in fusion reactors has been considered for neutron multiplication in breeding blankets and as an oxygen getter for plasma-facing surfaces." [28]

Beryllium has a strong cross session and a low atomic mass and this combination is ideal for its use in the neutron reflectors, placing this material as candidate for many blanket design [28].

The advantages in using Be as PFC are [18-28]:

1. Low Z material

2. Sputtering lower than carbon [27]

3. "Low radiative losses from the core plasma" [28]

4. Oxygen gathering

The experiment made at the Joint European Torus (JET) nuclear fusion plant, placed in Culham (UK), confirm the above mentioned characteristics [29,30].

The plasma material interaction of beryllium and plasma provokes the creation of beryllium oxides like $\mathrm{BeO}_{2}$ that, from one side, reduce the sputtering and from the other side enhance the $\mathrm{H}$ retention [31] to levels comparable to those of carbon oxides [32,33]. The experiments made on PISCE-B facility demonstrate that the $\mathrm{H}$ retention depends also from other impurities [34-36].

One of the flaw of Be is its low melting temperature $(1550 \mathrm{~K})$ that in future plants, like ITER, can provoke extended damages of PFCs in case of PMIs [37].

"The dynamics and loss of the layers of molten Be during transients, which are subject to forces associated with plasma impact, Lorentz forces, etc., it is yet to be studied in detail. The experience with Be in JET was recently reviewed $[38,39]$ with emphasis on the behavior and influence on the plasma of Be melting and molten Be-PFCs. In JET, a single large ELM depositing $~ 1 M J$ in less than $1 \mathrm{~ms}[39,40]$, led to substantial melting of the Be JET divertor target and terminated the high performance ELM-free phase of the discharge. However, the effects of Be melting on subsequent plasma operations were not catastrophic, due to the plasma's high tolerance to the Low-Z Be. Therefore, the precise implications of significant Be first-wall melting on the lifetime of the wall in ITER, and on the performance of a burning plasma experiment like ITER, are still not clear and require further study."

Another key safety issue is the toxicity of Be in case of inhalation, so it is necessary guarantee a continuous monitoring of air to prevent workers disease [28]. 


\subsection{Materials with High-Z}

"The major focus of research on High-Z materials in fusion devices has been the achievement of low core plasma contamination, due to the low 'fatal' core concentrations (for ignition 10-3-10-4 for Mo and W, respectively) in burning plasma experiments. The core concentration of High-Z impurities is controlled by both the impurity physical sputtering source at PFCs and impurity transport. High-Z materials have been used for the majority of PFCs in several large fusion experiments recently and in the past: Frascati Tokamak Upgrade (FTU) with molybdenum toroidal limiters [41], Alcator C-Mod with a molybdenum first wall and divertor [41,42], TEXTOR with High-Z components as limiters [43] and ASDEX-Upgrade both at the divertor [44] and main chamber [45]."

"In general, High-Z core concentrations decrease with increasing density [43,46,47], as expected from the reduction of physical sputtering with edge temperature, and are lower (by factors of 2.5-10) in the divertor than in limiter geometries [47-50]."

There are several studies [51-58] that have investigated the possibility to use tungsten and its alloys for the divertor and the first wall. EFDA has runned also a program (W\&WALLOYS) to analyze these applications for $\mathrm{W}[49,50,59,60]$.

DEMO, as ITER, will have the classic torus shape with the $85 \%$ of the inner surface that has to be covered with blanked boxes to convert the power coming from fusion reactors provoking the transmutation of Li in tritium [49].

Under normal condition an heat load of $2 \mathrm{MW} / \mathrm{m}^{2}$ can be reasonably expected so a potential structural material can be the ferritic-martensitic $9 \% \mathrm{Cr}$ steels with a protection layer based on $\mathrm{W}$ as armor material.

"Furthermore, the divertor is the highest thermally loaded components of a fusion power plant. About $15 \%$ of the total fusion power has to be removed by divertor while peak loads of 10-20 MW/m2 have to be considered. Like the protection layer of the first wall, the plasma facing divertor parts are intended to be made of tungsten or tungsten alloys. In helium cooled divertor designs tungsten materials are also considered for structural use (e.g., as pressurized pipes or thimbles) [49,50]. Since the requirements for both applications (armor or structure) are quite different, in this paper we distinguish between armor and structural materials which in both cases could be made of tungsten. In addition, all plasma facing components are exposed to fast neutrons. That means that the consequent damage, wear, and aging can reduce the durability of some divertor components significantly."

The anisotropic microstructure of $\mathrm{W}$ allow its use for fabrication of pipes and plates [61].

"So far, only rhenium is known to improve the ductility of tungsten by solid solution but its use for fusion energy applications has been ruled out for reasons of cost and irradiation embrittlement.

Iridium too is sometimes mentioned in literature as having a similar effect [62], though it is even more expensive. This leaves only tantalum, vanadium, molybdenum, and titanium which also form solid solution with tungsten ( $\mathrm{Cr}$ is excluded from this list since $\mathrm{W}-\mathrm{Cr}$ alloys are known for their brittleness). Round blanks of $\mathrm{W}-1 \% \mathrm{Ta}, \mathrm{W}-5 \% \mathrm{Ta}, \mathrm{W}-5 \% \mathrm{~V}, \mathrm{~W}-25 \% \mathrm{Mo}$, and $\mathrm{W}-50 \%$ Mo have been produced by PLANSEE (sintered in hydrogen atmosphere and forged to a deformation degree of $80 \%$ ). Charpy tests in the temperature range of 400-1100 ${ }^{\circ} \mathrm{C}$ (in vacuum) have shown that compared to pure tungsten the Ductile-Brittle Transition Temperature (DBTT) of all alloys is higher, i.e., they are more brittle. Therefore, it is assumed that tungsten cannot be ductilised by solid solution, except with rhenium (or maybe iridium). As a last option, however, the effect of titanium has still to be investigated. $[49,50] "$

Experiments to test thermal shock and fatigues have been performed in Jülich and Garching [63-65] varying the power flux from 0.19 and $1.13 \mathrm{GW} / \mathrm{m}^{2}$ and the temperature from $25^{\circ} \mathrm{C}$ to $400{ }^{\circ} \mathrm{C}$ with a load of pulsed from 100-1000 per 1 ms concluding that "the most promising material so far is $\mathrm{W}-1$ vol. $\% Y_{2} \mathrm{O}_{3}$ showing as yet no crack formation, while pronounced cracking is observed in $\mathrm{W}-5$ vol. $\% Y_{2} \mathrm{O}_{3}$ and W-5 wt.\%Ta materials under similar loadings [49,50]"

The loss of coolant accidents can provokes temperatures (in vessel) till $1200{ }^{\circ} \mathrm{C}$ that can oxide $\mathrm{W}$ causing a radioactive $\mathrm{W}$ oxides release [66].

"The linear oxidation rate of tungsten at $1000{ }^{\circ} \mathrm{C}$ is about $1.4 \times 10^{-2} \mathrm{mg} \cdot \mathrm{cm}^{-2} \cdot \mathrm{s}^{-1}$ [67], which in the approximately $1000 \mathrm{~m}^{2}$ DEMO first wall would correspond to a release of half a ton of tungsten oxides per 
hour. A way of avoiding this problem is the addition to tungsten of oxide-forming alloying elements leading to the growth of a self-passivating layer at high temperature in the presence of oxygen. During normal operation, the surface of this material will consist of pure tungsten, owing to preferential sputtering of the alloying elements. In previous studies the good performance of the system $\mathrm{W}$-Cr-Si manufactured via magnetron sputtering could be demonstrated [68]. Thin films of such alloys showed a strongly reduced oxidation rate compared to pure tungsten. However, the formation of brittle tungsten silicide may be disadvantageous for the powder metallurgical production of bulk W-Cr-Si alloys if a good workability is needed [49,50]."

Several oxidation tests have been made with different W-based alloys at a temperature of $1073 \mathrm{~K}$ for 3 hours (see Table 1 taken from [69]). Table 1 shows good results for Tungsten- Chromium- Titanium alloys. The amour of first wall needs a certain thickness (in the order of millimeters) using the above mentioned combinations (W-Cr-Si and W-Cr-Ti) obtaining a quasi-dense material $[49,50,70,71]$.

Table 1. Composition and results of the screening oxidation tests with different tungsten-based alloys at $1073 \mathrm{~K}$ for $3 \mathrm{~h}$. [69].

\begin{tabular}{cc}
\hline Alloy (wt.\%) & Oxidation Test Results \\
\hline $\mathrm{W}-\mathrm{Cr}_{14}-\mathrm{Ti}_{2}$ & Slow oxidation \\
$\mathrm{W}-\mathrm{Cr}_{18}-\mathrm{Ti}_{2}$ & Slow oxidation \\
$\mathrm{W}-\mathrm{Cr}_{16}-\mathrm{Zr}_{9}$ & Film delamination \\
$\mathrm{W}-\mathrm{Hf}_{17}-\mathrm{Ta}_{15}$ & Film delamination \\
$\mathrm{W}-\mathrm{Hf}_{32}-\mathrm{Ti}_{2}$ & Film delamination \\
$\mathrm{W}-\mathrm{Ta}_{12}-\mathrm{Ti}_{2}$ & Film delamination \\
$\mathrm{W}-\mathrm{Ta}_{12}-\mathrm{Zr}_{5}$ & Fast oxidation \\
$\mathrm{W}-\mathrm{Zr}_{2}-\mathrm{Ti}_{1}$ & Film delamination \\
$\mathrm{W}-\mathrm{Y}_{7}-\mathrm{Cr}_{3}$ & Relatively slow oxidation \\
$\mathrm{W}-\mathrm{Y}_{24}-\mathrm{Cr}_{2}$ & Film delamination \\
\hline
\end{tabular}

Table 2 shows the main characteristics of two alloys ( $\mathrm{W}-\mathrm{Cr}_{10}-\mathrm{Si}_{10}$ and $\left.\mathrm{W}-\mathrm{Cr}_{12}-\mathrm{Ti}_{2.5}\right)$ [71-73].

Table 2. Characteristics of two W based alloys [49].

\begin{tabular}{cccc}
\hline Material & Oxidation behavior & Thermal Conductivity & DBTT \\
\hline W-Cr ${ }_{10}-\mathrm{Si}_{10}$ & $\begin{array}{c}\text { Lower at } 600{ }^{\circ} \mathrm{C} \\
\text { Higher at } 1000{ }^{\circ} \mathrm{C}\end{array}$ & $16 \mathrm{~W} / \mathrm{m} \mathrm{K}$ at $500{ }^{\circ} \mathrm{C}$ & $1000-1050{ }^{\circ} \mathrm{C}$ \\
& $\begin{array}{c}\text { In comparison with thin films that have the same composition } \\
\text { Same at } 600{ }^{\circ} \mathrm{C}\end{array}$ & \\
$\mathrm{W}-\mathrm{Cr}_{12}-\mathrm{Ti}_{2.5}$ & $\begin{array}{c}\text { Higher at } 800 \text { \& } 1000^{\circ} \mathrm{C} \\
\end{array}$ & $50 \mathrm{~W} / \mathrm{m} \mathrm{K}$ at $500-600{ }^{\circ} \mathrm{C}$ & $900{ }^{\circ} \mathrm{C}$ \\
\hline
\end{tabular}

"So far, thin tungsten plates show the best ductility, as long as specific fabrication or machine rules are followed: (1) stress concentrators have to be avoided and (2) the anisotropic microstructure has to be aligned to the contour of the according part. Joining of tungsten materials is possible, but design routes, cost and low-activation criteria probably have to be redefined for brazing materials. A complete picture of the irradiation performance of tungsten materials is not yet available. But for further, more specific designs at least, basic irradiation damage data have to be produced. This, together with the aforementioned issues, should be at the top of the priority list of fusion material programs in general" [49].

\subsection{Austenitic and Ferritic/Martensitic Steels and Other Advanced Materials}

"It is impressive how the world of nuclear fusion research and the world of nuclear fission research have been in touch during these last decades exchanging ideas, new research achievements and resources." One of the scientific discipline that has deeply strongly tapped this dual-use approach is the material science (see Figure 3). 


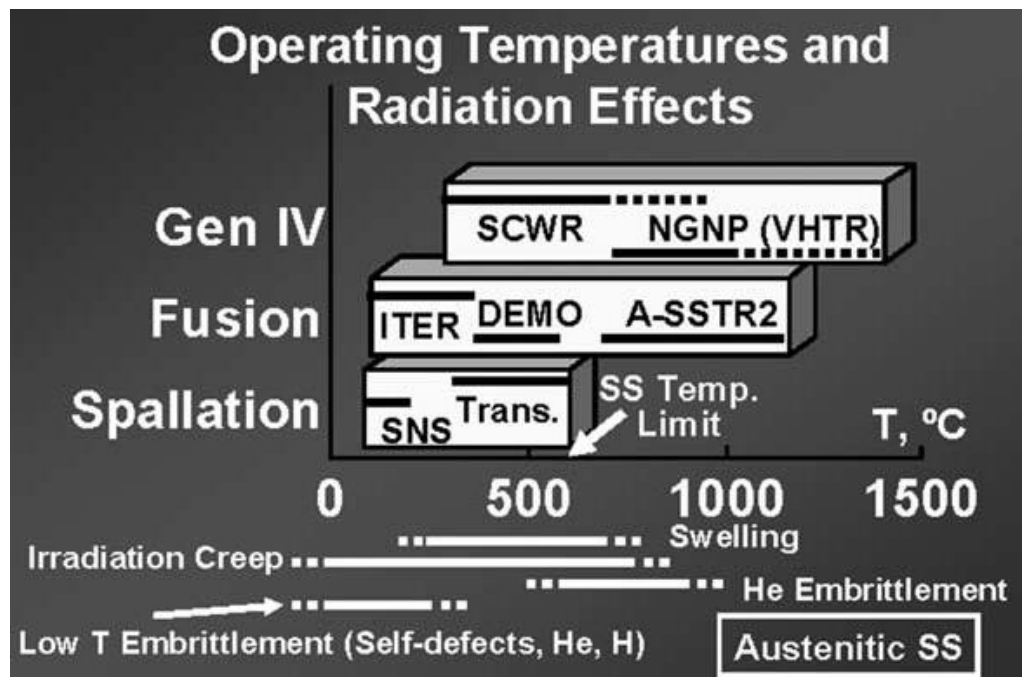

Figure 3. Overlap in temperatures for fusion, fission and spallation facilities. This figure is taken from [18].

One of the main fusion nuclear reactor difference if compared with the nuclear fission reactors is the high production of $\mathrm{He}$ and $\mathrm{H}$ that "require special mitigation techniques to minimize cavity swelling and embrittlement. At low temperatures, defect cluster accumulation in the matrix can produce high hardening with accompanying embrittlement and the localized deformation phenomenon is known as dislocation channeling may create high stress concentrations at grain boundaries. At high temperatures, formation of helium cavities at grain boundaries can lead to severe inter granular embrittlement. Therefore, the matrix regions and grain boundaries must be designed to mitigate the severe neutron radiation effects. Finally, the unique requirement to restrict alloying compositions to so-called "reduced activation" elements in order for fusion to achieve its environmental "low-impact" potential produces considerable constraint on the number of options for development of improved materials" [5].

These challenges are faced by the production of advanced material with unique performances [74-78], these material include ferritic/martensitic steels, $\mathrm{V}-\mathrm{Cr}-\mathrm{Ti}$ alloys and $\mathrm{SiC} / \mathrm{SiC}$ ceramic composites.

"There is an overlap between the temperatures of fusion, fission and spallation facilities as showed in Figure 2" taken from [78].

"In Table 3 is it possible read also the main operating parameters of these three types of plants [78]."

Table 3. Summary of operating parameters for fusion, fission and spallation facilities. This table is taken from [78].

\begin{tabular}{llll}
\hline Parameter & Fusion & Fission (Generation IV) & Spallation \\
\hline Working fluid & $\mathrm{H}_{2} \mathrm{O}, \mathrm{He}, \mathrm{Li}, \mathrm{PbLi}, \mathrm{FLiBe}$ & $\mathrm{H}_{2} \mathrm{O}(\mathrm{SC}), \mathrm{He}, \mathrm{Na}, \mathrm{Pb}, \mathrm{PbBi}$ & $\mathrm{Hg}, \mathrm{PbBi}, \mathrm{H}_{2} \mathrm{O}$ \\
Energy & $<14,1 \mathrm{MeV}$ & $<1-2 \mathrm{MeV}($ most $\mathrm{n})$ & $\leqslant 1 \mathrm{GeV}(\mathrm{p}$ and $\mathrm{n})$ \\
$\mathrm{He} / \mathrm{dpa}{ }^{*}$ & 10 & $0,1-50$ & $50-100$ \\
Stresses & Moderate, slow varying & Moderate, slow varying & High pulsed \\
\hline
\end{tabular}

* dpa: displacement per atom. ${ }^{* *}$ For normal operation. In a plasma disruption the stresses to the structure are to "high transient". High, for both fusion and spallation, indicates stresses levels that are near the allowable maximum fraction of yield stresses under applicable engineering design rules.

"We can divide the materials into two main groups: steels (austenitic and ferritic/martensitic) and other advanced materials. Although there are very significant differences in the fusion, fission and spallation environments, there is a range of performance-limiting phenomena arising from radiation effects that are common to all nuclear environments. However, to illustrate the similarities in challenges, the operating requirements for two of the principal structural materials used in component design, austenitic stainless steels and ferritic/martensitic stainless steels, are summarized in Tables 4 and 5 taken from [78] and Table 1 in [79] shows a list of commercial and research steels [79-81]." 
Table 4. Austenitic stainless steels: spallation, fusion, and Generation IV fission applications. Asterisks indicate conditions set for removal of first target. Later targets may be subjected to higher doses and transmutation levels with experience gained in conditions specific to SNS. This table is taken from [78].

\begin{tabular}{|c|c|c|c|c|c|}
\hline $\begin{array}{c}\text { System } \\
\text { (Working Fluid) }\end{array}$ & Component & $\mathbf{T}^{\circ} \mathrm{C}$ & $\begin{array}{l}\text { Max dose, } \\
\text { dpa }\end{array}$ & $\begin{array}{l}\text { Maximum He, } \\
\text { ppm }\end{array}$ & Candidate Alloys \\
\hline SNS $^{\text {a }}$ (mercury) & Spallation target module & $80-150$ & 5 & 200 & $316 \mathrm{LN}$ \\
\hline ITER (water) & First wall/Blanket & $100-300$ & 3 & 75 & $316 \mathrm{LN}$ \\
\hline $\mathrm{SCWR}^{\mathrm{b}}$ & Fuel assembly & $280-620$ & 15 & 200 & Advanced low swelling \\
\hline $\mathrm{SC}^{\mathrm{c}}$ (water) & Core support/internals & $280-500$ & $0,1-20$ & 250 & steels: D9, PN316, HT-UPS \\
\hline
\end{tabular}

Table 5. Ferritic/martensitic steels: fusion, and Generation IV fission applications. This table is taken from [77].

\begin{tabular}{|c|c|c|c|c|c|}
\hline $\begin{array}{c}\text { System } \\
\text { (Working Fluid) }\end{array}$ & Component & $\mathrm{T}^{\circ} \mathrm{C}$ & $\begin{array}{l}\text { Max dose, } \\
\text { dpa }\end{array}$ & $\begin{array}{c}\text { Maximum He, } \\
\text { ppm }\end{array}$ & Candidate Alloys \\
\hline SSTR $^{\mathrm{a}}$ (water) & First wall/blanket & $300-550$ & 100 & $>1000$ & \multirow{3}{*}{$\begin{array}{l}\text { Low activation } 8 \%-9 \% \mathrm{Cr} \\
\text { ferritic-martensitic steels }\end{array}$} \\
\hline $\operatorname{HCLL}^{b}(\mathrm{He})$ & First wall/blanket & $270-550$ & 100 & $>1000$ & \\
\hline $\operatorname{HPBC}^{\mathrm{c}}(\mathrm{He})$ & First wall/blanket & $300-550$ & 100 & $>1000$ & \\
\hline & Fuel assembly & $280-620$ & 15 & 20 & \multirow{3}{*}{$\begin{array}{c}\text { Advanced } 8 \%-12 \% \\
\text { ferritic-martensitic steels }\end{array}$} \\
\hline SCWR (SC water) & Core support/internals & $280-500$ & $0,1-20$ & 20 & \\
\hline $\mathrm{FR}^{\mathrm{d}}(\mathrm{Pb}-\mathrm{Bi}, \mathrm{Pb})$ & Fuel assembly & $300-550$ & 150 & 15 & \\
\hline
\end{tabular}

Actually the use of stainless steel has not been planned for nuclear plants like ITER because of its low thermal conductivity and He embrittlement. The worldwide research for DEMO is actually focused on 8-9 Chrome ferritic/martensitic steels [82-86].

"Several high-priority near-term potential research activities to address fusion nuclear science challenges are summarized". General recommendations are reported in [87].

The operating temperature strongly influence the microstructural features [88-90] and the PMIs include several phenomena over different range of time and length scale reported in Figure 4 taken from [87].

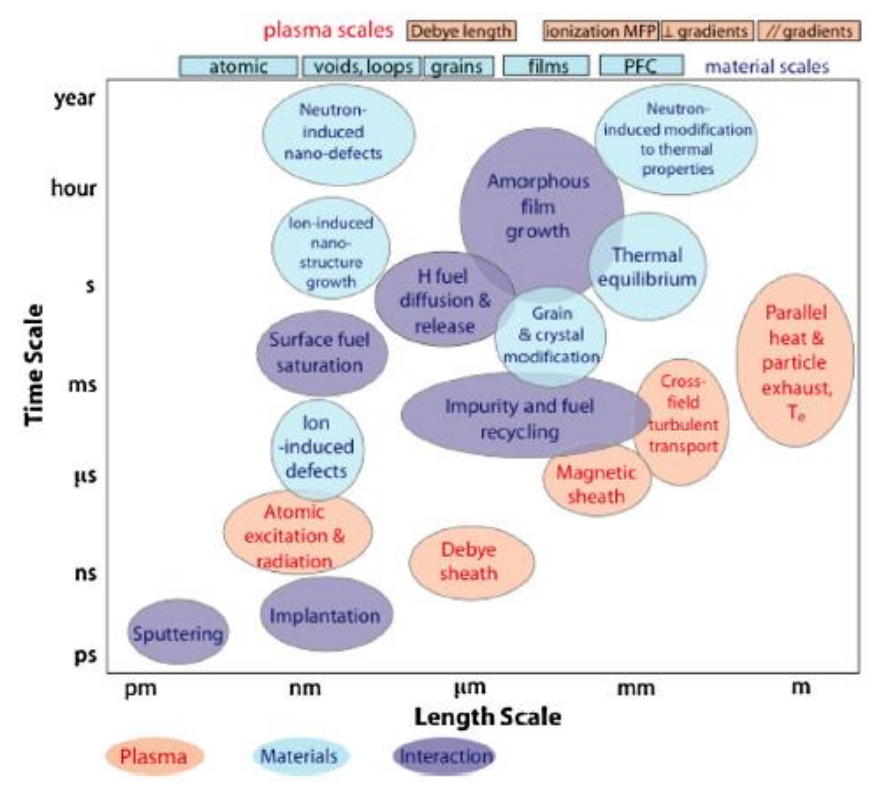

Figure 4. Overview of the coupled multi-scale phenomenon associated with plasma-materials interactions. This figure is taken from [87]. 
"Regarding the materials for material structures, the overarching challenge is to maintain mechanical and structural integrity by designing highly efficient radiation self-healing nanostructures that are resistant to unprecedented levels of displacement damage and nuclear transmutation products. Atomic displacement damage in a DEMO reactor corresponds to ejecting every atom from its lattice site more than 50-150 times. The conversion of fusion power to practical electricity and the creation of fusion fuel in the blanket, tritium systems, and balance of plant regions is a complex topic involving multiple scientific phenomena. Between the PFCs, the tritium fueling, purification and recycle components and the heat exchangers, the tritium concentration and neutron flux will vary by over 10 orders of magnitude and the temperature and magnetic field will vary by several orders of magnitude, and span different regimes of physics and chemistry predominance [91]. A broad and fundamental science-based approach is needed to meet this challenge. In order to appropriately position the technological maturity of PFCs, materials, blanket, and tritium technology for potential next step devices following ITER, it is imperative to initiate or enhance modest research activities on fusion nuclear technology. Numerous opportunities for high-impact fusion research may be achievable by making modifications to existing facilities and/or moderate investment in new medium-scale facilities [87]."

In conclusion, it is possible to affirm that several research programs have been developed and are in progress to find the proper solutions to choose the right materials for the future nuclear plants like ITER or DEMO, you can read also [92-135] to go into the details of the most important research in progress. Another important conclusion is that the research programs for the materials that are used in nuclear fission plants can be a source of ideas and information for nuclear fusion research framework.

\section{Materials and Methods}

The previous sections put in evidence that the material selection from future nuclear plans (like ITER or DEMO) is one of the most important scientific challenge to let the nuclear fusion be a real alternative for energy production. Another key point is that the PMIs are inevitable so as the formation of dust, flakes and composites from PFCs due to PMIs. Accidents provoking vacuum failures and coolant dispersions (LOVA or LOCA) can jeopardize the functionality of the nuclear plants provoking dust re-suspension inside the vacuum vessel, this re-suspension can damage the plants causing explosions and can be dangerous for the health of operators because of its toxicity, radioactivity and capability to chemical react. In order to face these security and safety problems the Quantum Electronic and Plasma Physics (QEP) Research Group of University of Rome Tor Vergata in collaboration with ENEA Fusion Technology of Frascati (Italy) has developed a facility, STARDUST, in order to reproduce experimental conditions comparable to those expected in ITER in case of LOVA or LOCA in order to get a mathematical model to predict dust re-suspension. STARTDUST facility showed limits and it has been upgraded, the new facility is STARDUST-U. The dimension of dust created inside the tokamaks that are used worldwide is in the range $0,1-1000 \mu \mathrm{m}$ and the most dangerous for the respiratory system are the one in the range $0,1-1 \mu \mathrm{m}$ that can be withheld from the lungs. These particle dimensions, in the pressurization regime used inside STARDUST and STARDUST-U, has a behaviour comparable to those of the air streamlines and this is way in this work we will analyse the thermodynamic behaviour both from an experimental and numerical point of view [136-149].

STARDUST-U (Acronyms for Small Tank for Aerosol Removal and DUST-Upgrade) is an experimental facility build in 2014 by the QEP research group in order to get experimental data necessary to run numerical simulations and validate the mathematical models necessary to predict dust resuspension. It has been obtained through a structural and mechanical upgrade of STARDUST facility. It has been build up to reproduce thermos-fluid dynamic conditions comparable to those expected in a fusion reactor vessel during vacuum failures [136-149]. The vacuum failures are replicated through the inlet of pressurized air by different ports of the facility (C-D-E-F, see Figure 5). 


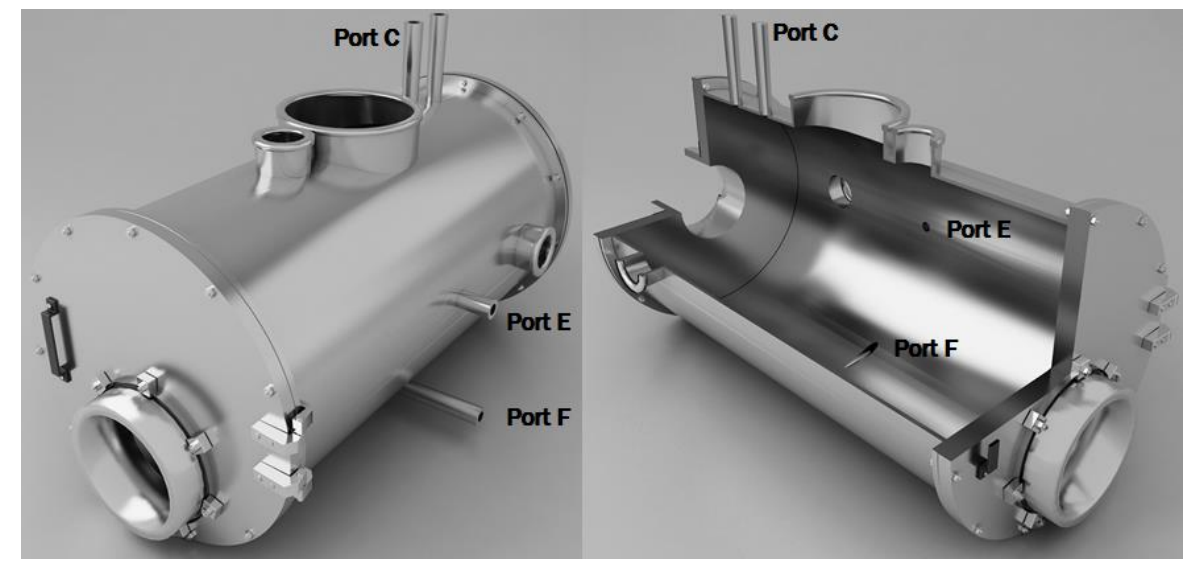

Figure 5. STARDUST-Upgrade facility rendering, showing ports $\mathrm{C}, \mathrm{E}$ and $\mathrm{F}$ used in the present campaign.

The data collected inside STARDUST-U are:

- $\quad$ static pressure inside the chamber $(\mathrm{Pa})$,

- $\quad$ average temperature of the chamber $(\mathrm{K})$,

- air volume flow-rate in liters per minute ( $\mathrm{L} / \mathrm{min})$,

- differential pressure from transducers in selected locations (Pa), local air velocity $(\mathrm{m} / \mathrm{s})$ and corresponding Mach Number (Ma).

All this data is collected by a National Instruments cards system able to store (with a frequency of $50 \mathrm{~Hz}$ ) the information coming from the hardware placed on the facility.

Static pressure was measured with a Pressure gauges (Alcatel AP 1004 Pirani Gauge, Alcatel Vacuum Technology, Annecy, France [135]), temperature with three J-thermocouples, flow rate with MKS flow meter (1559A Mass-Flo Controller, MKS Instruments, Andover, Ma, USA [135]) that covers the range from 20 to 200 standard L/min, differential pressure from Kulite piezo resistive transducers (XCE-093-2D High Temperature Miniature Pressure Transducers [135]). Voltage signal from transducers was converted into differential pressure $(\mathrm{Pa})$ according to transducers sensitivity and allowed to calculate local air velocity and Ma in the locations where the transducers have been placed for each replication.

In order to replicate the vacuum failure accidental event expected, an integrated LabVIEW control system was developed to correctly set up the border conditions, and to control and acquire the thermofluid-dynamic variables throughout the experiment. Standard Procedures of a typical run are summarized in Figure 6.

In the experimental campaign presented in this paper, LOVAs have been reproduced as air intake from three different inlet ports (ports C, E, F; Figure 6), corresponding to upper, mid-plane, and lower part of the facility. Two different air flow-rates have been used (27 and $40 \mathrm{~L} / \mathrm{min})$, allowing to reproduce two different pressurization rates. A vacuum pump connected with the chamber allowed to set to $300 \mathrm{~Pa}$ the initial vacuum level for each replication (only for port $\mathrm{C}$ the experiments have been conducted also starting from $2000 \mathrm{~Pa}$ ). Data acquisition was triggered by the on/off electro valve opening that allowed the air to enter the chamber from the selected port replicating the breach of a vacuum failure. Three replications have been performed for each experiment. Diagnostics data regarding internal static pressure, average temperature and air volume flow rate will be shown for one of the three set-ups, i.e., port $C$, while the two others, having the same trend, have been omitted. For the three experimental set-ups (i.e., upper, mid-plane and lower vacuum failures respectively from ports $\mathrm{C}, \mathrm{E}, \mathrm{F})$, transducers positions inside the chamber will be shown, along with corresponding air velocity and Ma trends over time. Experimental results (presented with error tube calculated according to error analysis presented below) are compared with numerical results from simulations performed with ANSYS CFX 16.0 using SST k- $\omega$ turbulence model with $\gamma-\vartheta$ transitional model. 


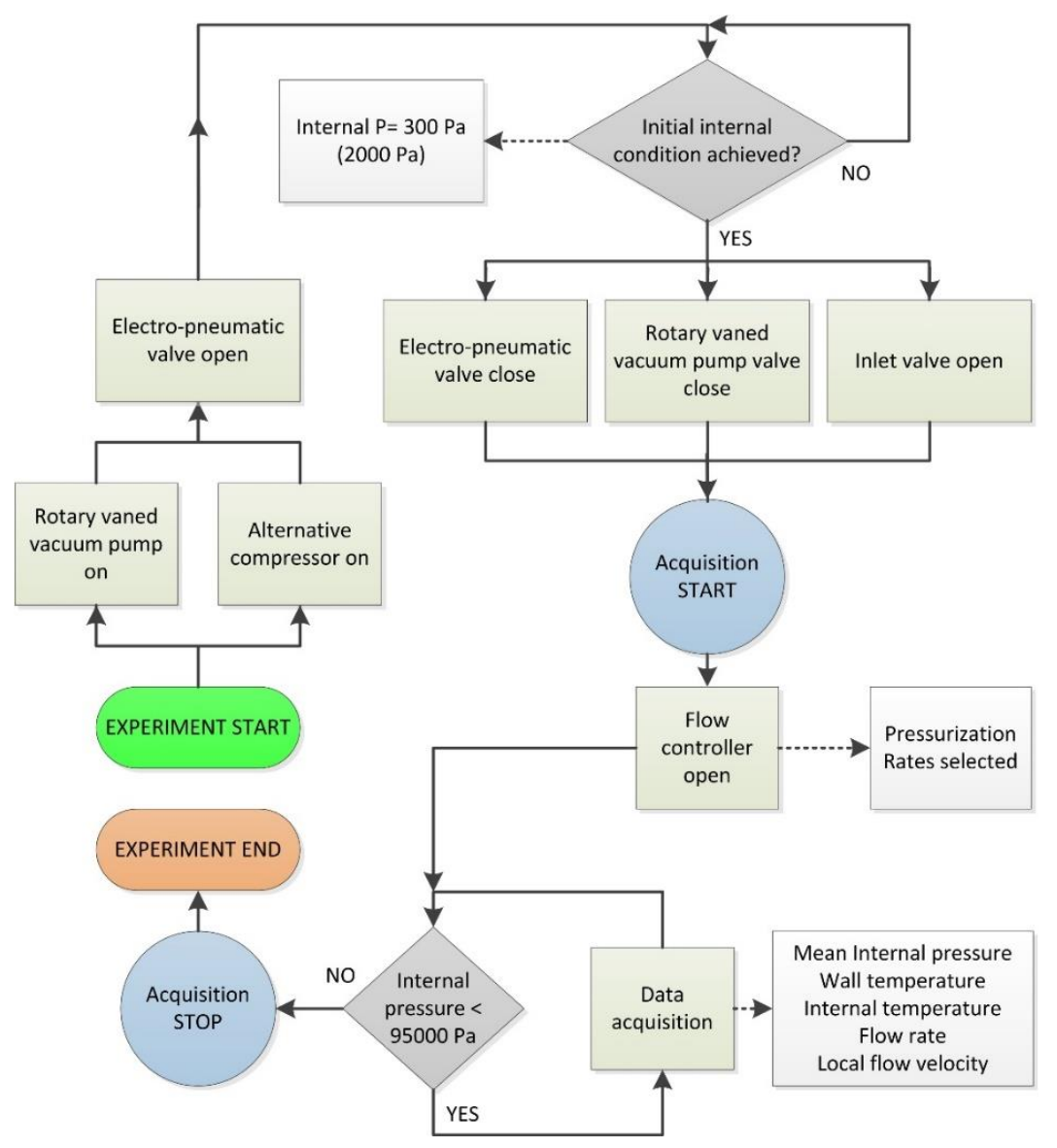

Figure 6. STARDUST-Upgrade facility standard procedures flowchart.

Acquisition system for each replication provides a data files where the following quantities are listed: observation no., actual internal static pressure (Pa), j-thermocouples temperatures $\left({ }^{\circ} \mathrm{C}\right)$, air volume flow rate $(\mathrm{L} / \mathrm{min})$, differential pressure voltage signal from transducers $(\mathrm{mV})$.

The replications were elaborated to calculate the average local air velocity and Ma average for each experiment using a script developed with Matlab.

According to the First Law of Thermodynamics for an open system, assuming steady state operations, altitude term negligible, isentropic process (no heat transfer), no work done, and considering compressible air as a perfect gas, its local velocity and Ma can be determined as in the Equation (1):

$$
v=\sqrt{\frac{2 k}{k-1} \frac{R \bar{T}}{M}\left[\left(\frac{P_{\Delta}}{P_{S}}+1\right)^{\frac{k-1}{k}}-1\right]},
$$

where:

- $\quad k=c_{p} / c_{v}$ Ratio of the fluid specific heat at constant pressure $c_{p}$ to the fluid specific heat at constant volume $c_{v}$ (it is approximately equal to 1.4 for air at standard condition);

- $\quad R=8.314 \mathrm{JK}^{-1} \mathrm{~mol}^{-1}$ Universal gas constant;

- $\quad M=0.028968 \mathrm{~kg} / \mathrm{mol}$ Dry air molecular mass at standard conditions.

- $\quad \bar{T}=\frac{1}{N} \sum_{i=1}^{N} T_{i}$ Mean temperature in the transducer's positions from $i$ thermocouples (K);

- $\quad P_{S}(P a)$ Static pressure (measured by Pirani pressure gauge);

- $\quad P_{\Delta}=P_{T}-P_{S}(P a)$ Differential pressure (measured by pressure transducers as difference between its head pressure and its reference tube pressure);

- $\quad P_{T}(\mathrm{~Pa})$ Total pressure (measured by the transducers head). 
"However, experimental measurements are affected by direct errors and propagation of uncertainty in case of indirect measurements, like in this case velocity and $M a$. If the three uncertainties $\Delta x_{1}, \Delta x_{2}, \Delta x_{3}$ on the variables of the velocity function $v=f\left(x_{1}, x_{2}, x_{3}\right)$ are not likely of the same sign, and if variables correlations are neglected, and if this applies also to the Ma function $M a=g\left(y_{1}, y_{2}\right)$, it is possible to use the following Equations 2 and 3 [135-145] respectively for total uncertainty $\Delta v$ of velocity and $\Delta M a$ of Ma."

$$
\begin{gathered}
\Delta \mathrm{v}=\sqrt{\left[\left(\frac{\partial \mathrm{f}}{\partial \mathrm{x}_{1}}\right) \Delta \mathrm{x}_{1}\right]^{2}+\left[\left(\frac{\partial \mathrm{f}}{\partial \mathrm{x}_{2}}\right) \Delta \mathrm{x}_{2}\right]^{2}+\left[\left(\frac{\partial \mathrm{f}}{\partial \mathrm{x}_{3}}\right) \Delta \mathrm{x}_{3}\right]^{2}} \text {, and } \\
\Delta \mathrm{Ma}=\sqrt{\left[\left(\frac{\partial \mathrm{g}}{\partial \mathrm{y}_{1}}\right) \Delta \mathrm{y}_{1}\right]^{2}+\left[\left(\frac{\partial \mathrm{g}}{\partial \mathrm{y}_{2}}\right) \Delta \mathrm{y}_{2}\right]^{2}}
\end{gathered}
$$

where $x_{1}=\bar{T}$ (mean temperature from J-thermocouples), $x_{2}=P_{S}$ (static pressure from Pirani pressure gauge), $x_{3}=P_{\Delta}$ (differential pressure from Kulite pressure transducers), $y_{1}=x_{1}, y_{2}=v$ (local air velocity).

$$
\begin{gathered}
\frac{\partial \mathrm{f}}{\partial \mathrm{x}_{1}}=\frac{1}{2 \overline{\mathrm{T}}} \sqrt{\frac{2 \mathrm{k}}{\mathrm{k}-1} \frac{\mathrm{RT}}{\mathrm{M}}\left[\left(\frac{\mathrm{P}_{\Delta}}{\mathrm{P}_{\mathrm{S}}}+1\right)^{\frac{\mathrm{k}-1}{\mathrm{k}}}-1\right]} \\
\frac{\partial \mathrm{f}}{\partial \mathrm{x}_{2}}=\frac{\mathrm{P}_{\Delta} \mathrm{R} \overline{\mathrm{T}}\left(\frac{\mathrm{P}_{\Delta}}{\mathrm{P}_{\mathrm{S}}}+1\right)^{-\frac{1}{\mathrm{k}}}}{\mathrm{MP}_{\mathrm{S}}^{2} \sqrt{\frac{2 \mathrm{k}}{\mathrm{k}-1} \frac{\mathrm{RT}}{\mathrm{M}}\left[\left(\frac{\mathrm{P}_{\Delta}}{\mathrm{P}_{\mathrm{S}}}+1\right)^{\frac{\mathrm{k}-1}{\mathrm{k}}}-1\right]}} \\
\frac{\mathrm{x}_{3}}{=}=\frac{\mathrm{RT}\left(\frac{\mathrm{P}_{\Delta}}{\mathrm{P}_{\mathrm{S}}}+1\right)^{-\frac{1}{\mathrm{k}}} \sqrt{\frac{2 \mathrm{k}}{\mathrm{k}-1} \frac{\mathrm{R} \overline{\mathrm{T}}}{\mathrm{M}}\left[\left(\frac{\mathrm{P}_{\Delta}}{\mathrm{P}_{\mathrm{S}}}+1\right)^{\frac{\mathrm{k}-1}{\mathrm{k}}}-1\right]}}{\frac{\partial \mathrm{g}}{\partial y_{1}}=-\frac{v}{2 \overline{\mathrm{T}}^{1.5} \sqrt{k R / M}} ;} \\
\frac{\partial \mathrm{g}}{\partial y_{2}}=\frac{1}{\sqrt{k R \overline{\mathrm{T}} / M}}
\end{gathered}
$$

Uncertainties $\Delta x_{1}, \Delta x_{2}, \Delta x_{3}, \Delta y_{1}, \Delta y_{2}$ (direct errors) on the corresponding variables are [23]: $\Delta x_{1}=0.0031 \Delta \bar{T}(t), \Delta x_{2}=0.1 \Delta P_{S}(t)$ (Pirani pressure range: from 0.0005 to $1000 \mathrm{mbar}$ ), $\Delta x_{3}=0.1 \Delta P_{\Delta}(t)$, $\Delta y_{1}=\Delta x_{1}, \Delta y_{2}=\Delta v$, where $\bar{T}(t), P_{S}(t)$ and $P_{\Delta}(t)$ are functions of time, acquired throughout the experiments." [134-149].

\section{Results and Discussion}

\subsection{Experimental Campaign}

The experimental set-up (see Section 4) allow to reproduce different LOVA and LOCA accidents by flowing compressed air inside the experimental facility (STARDUST-U) in order to get the data that allow a thermo-fluid dynamics analysis of those accidents inside the facility.

The values measured and collected are:

- $\quad$ Flow rate measures (through the flow meters)

- Pressure rates (through pressure gauges)

- Temperatures rates (through thermocouples)

- Punctual velocity values (through pressure transducers) 
These values are collected and stored with a frequency of $50 \mathrm{~Hz}$ and have a dual function: give the proper boundary conditions to run the simulation and be used as comparison data to validate the output of the simulation that means validate the mathematical model to predict the consequences of a LOVA or LOCA accidents on dust resuspension.

The experimental campaign discussion will be divided into two sub-section:

- Experimental results get reproducing the LOCA accident through an air injection from valve $C$ and $D$

- Experimental results get reproducing the LOVA accident through an air injection from valve $\mathrm{E}$ and $\mathrm{F}$

The boundary conditions used to experimentally reproduce the accidents (from Valve C, D, E, F) are:

- Initial pressure of the compressed air that has to be flowed in the facility: 2,8 bar

- Initial pressure inside the chamber: $200 \mathrm{~Pa}$

- Final pressure inside the chamber: $95000 \mathrm{~Pa}$

- Environmental temperature: $25^{\circ} \mathrm{C}$

- Three different inlet air flow rates:

1. $8 \mathrm{~L} / \mathrm{min}$ (to reproduce a pressurization rate of $100 \mathrm{~Pa} / \mathrm{s}$ inside STARDUST-U)

2. $27 \mathrm{~L} / \mathrm{min}$ (to reproduce a pressurization rate of $300 \mathrm{~Pa} / \mathrm{s}$ inside STARDUST-U as suggested by the GSSR)

3. $40 \mathrm{~L} / \mathrm{min}$ (to reproduce a pressurization rate of $500 \mathrm{~Pa} / \mathrm{s}$ inside STARDUST-U)

For each combination, three replications were made. The results showed the average of the three replication.

\subsection{Experiments from Valve C and D (LOCA Accidents Reproduction)}

Figures 7-9 shown the variations of internal pressure, temperature and flow rate during the accident replication (with the calculated error bar).

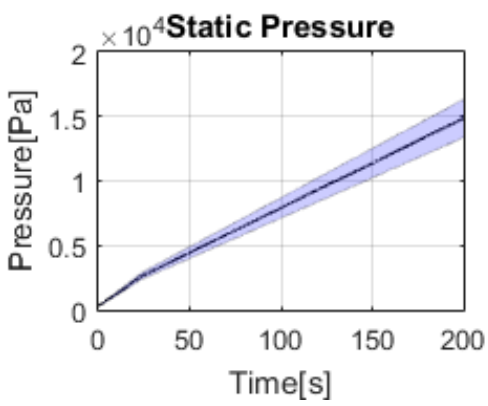

(a)

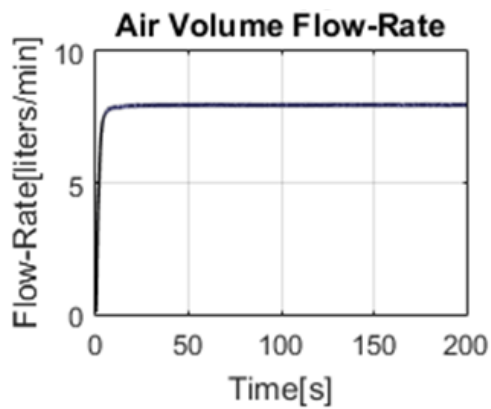

(c)

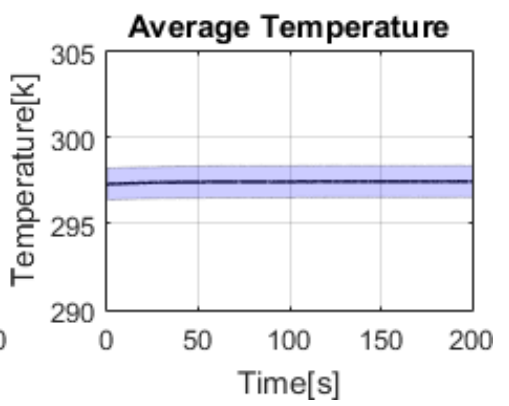

(b)

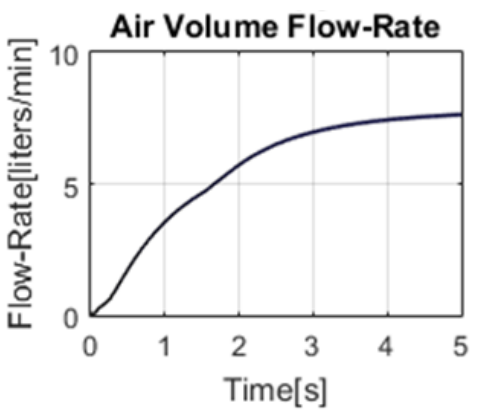

(d)

Figure 7. (a) Description of the pressure increase inside STARDUST-U during the air flow inlet at $8 \mathrm{~L} / \mathrm{min}$. (b) Description of the temperature variations measured during the experiment. (c) Description of the flow rate variation in the time. (d) Flow rate increase in the early stage from the accident experimental simulation. 

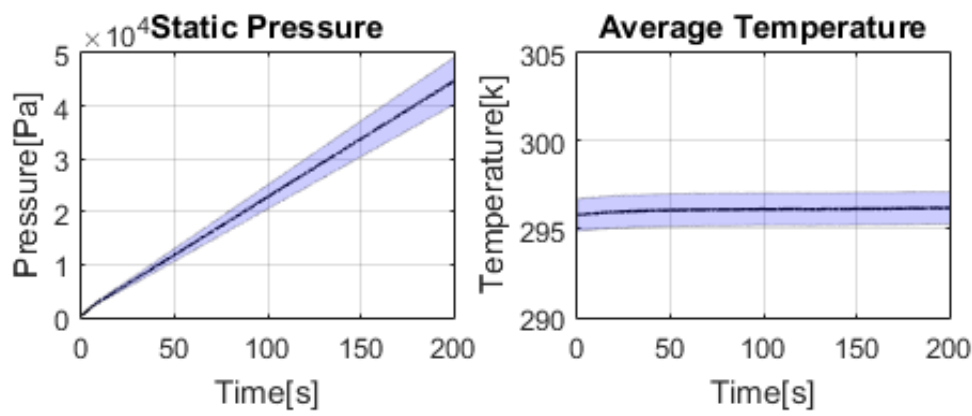

(a)

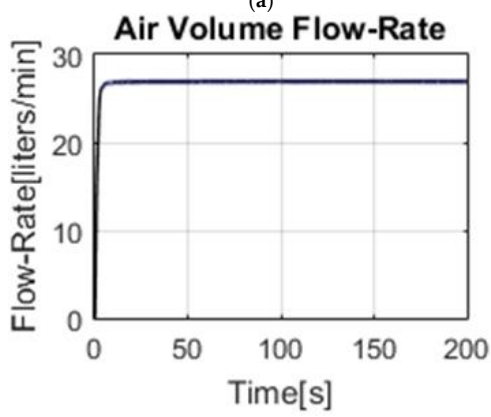

(b)

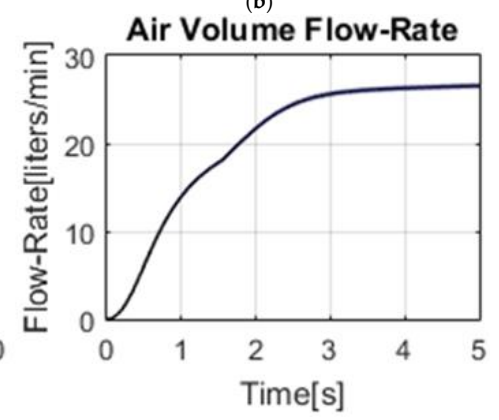

(c)

(d)

Figure 8. (a) Description of the pressure increase inside STARDUST-U during the air flow inlet at $27 \mathrm{~L} / \mathrm{min}$. (b) Description of the temperature variations measured during the experiment. (c) Description of the flow rate variation in the time. (d) Flow rate increase in the early stage from the accident experimental simulation.
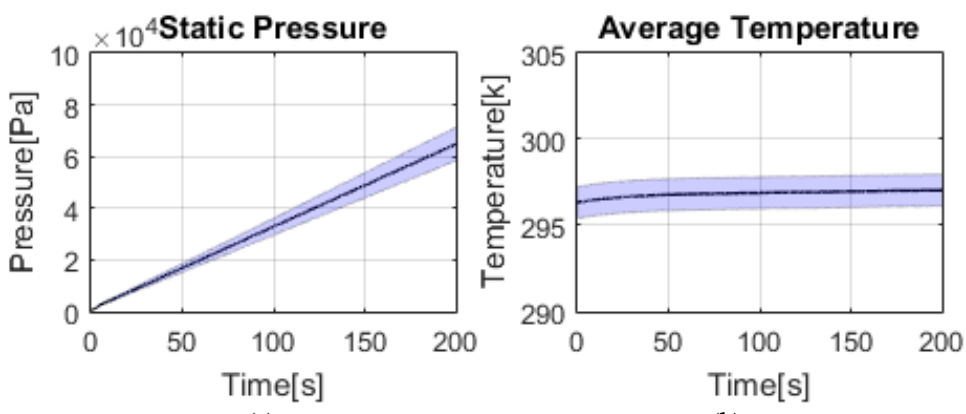

(a)

(b)

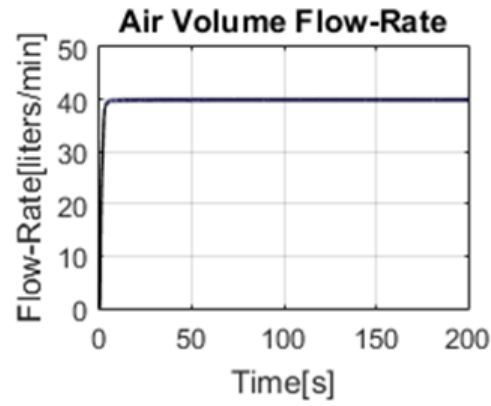

(c)

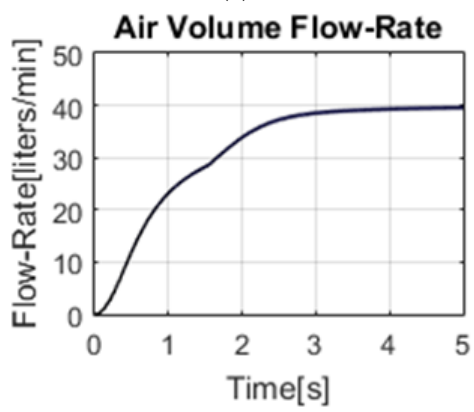

(d)

Figure 9. (a) Description of the pressure increase inside STARDUST-U during the air flow inlet at $40 \mathrm{~L} / \mathrm{min}$. (b) Description of the temperature variations measured during the experiment. (c) Description of the flow rate variation in the time. (d) Flow rate increase in the early stage from the accident experimental simulation. 
The results of pressure variations, flow rate variations and temperature variation obtained for vale $\mathrm{D}$ are comparable to those obtained for valve $\mathrm{C}$.

For the three different conditions $(8 \mathrm{~L} / \mathrm{min}, 27 \mathrm{~L} / \mathrm{min}$ and $40 \mathrm{~L} / \mathrm{min})$ the first diagram shows the internal pressure trend of the chamber from the initial pressure of $200 \mathrm{~Pa}$ to atmospheric pressure. The blue line is the value detected by the measuring instruments (Edward or Pirani). The red line represents the minimum error value, while the green line is the maximum error value. The internal pressure has a linear trend and reaches the fixed boundary conditions in about $1200 \mathrm{~s}$ for flow rate of $8 \mathrm{~L} / \mathrm{min}, 400 \mathrm{~s}$ for flow rate of $27 \mathrm{~L} / \mathrm{min}$ and 250 for flow rate of $40 \mathrm{~L} / \mathrm{min}$. It is very interesting see how the slop of the pressure diagram increase with the increasing of the flow rate from $8 \mathrm{~L} / \mathrm{min}$ to $27 \mathrm{~L} / \mathrm{min}$ with a percentage of almost $100 \%$ and from $27 \mathrm{~L} / \mathrm{min}$ to $40 \mathrm{~L} / \mathrm{min}$ with a percentage of almost $60 \%$. It means that it is not possible to go over the $1000 \mathrm{~Pa} / \mathrm{s}$ as accident simulation with this facility because the maximum flow rate achievable is $100 \mathrm{~L} / \mathrm{min}$. (see Figure 10).

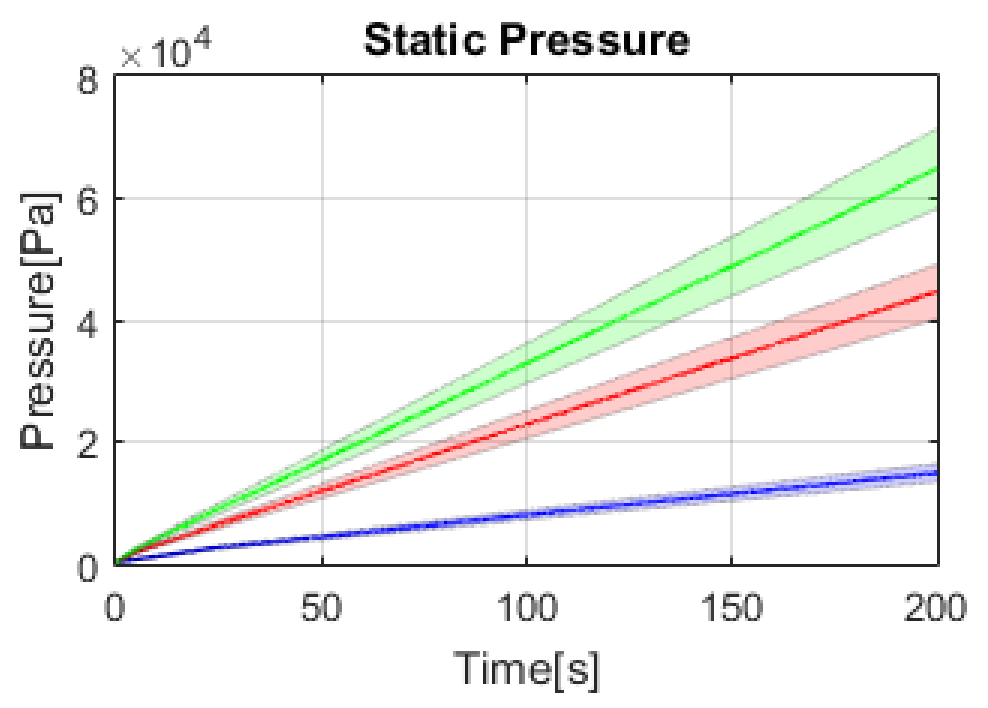

Figure 10. Comparison of the three pressure diagrams, $8 \mathrm{~L} / \mathrm{min}$ (blue diagram), at $27 \mathrm{~L} / \mathrm{min}$ (red diagram) and $40 \mathrm{~L} / \mathrm{min}$ (red diagram).

In the second graphic the mean temperature, evaluated by thermocouples, is shown. In the same way, the blue line is the value detected by the measuring instruments, the red line represents the minimum error value, while the green line is the maximum error value. It is possible see that the measured error is very low for this measure. For the two graphs, error bars are used with temporal spacing of $80 \mathrm{~s}$ for flow rate of $8 \mathrm{~L} / \mathrm{min}, 30 \mathrm{~s}$ for flow rate of $27 \mathrm{~L} / \mathrm{min}, 16 \mathrm{~s}$ for flow rate of $40 \mathrm{~L} / \mathrm{min}$, to make legible graphics.

The third graph shows the flow rate trend, while the last diagram shows the flow rate trend for the first 6 second of the experiment. The flow rate reaches the fixed value around $6 \mathrm{~s}$.

Figure 11 shows the variation of velocity measure by pressure transducer placed at $1 \mathrm{~cm}$ from valve $C$ with the air flowed from valve $C$ at $8 \mathrm{~L} / \mathrm{min}$ (blue diagram), at $27 \mathrm{~L} / \mathrm{min}$ (red diagram) and $40 \mathrm{~L} / \mathrm{min}$ (red diagram) with the related error reference tube. 


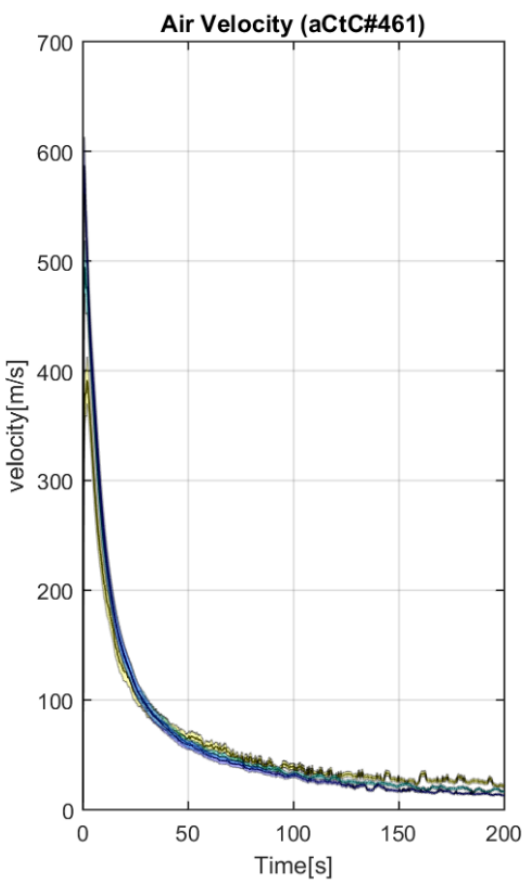

(a)

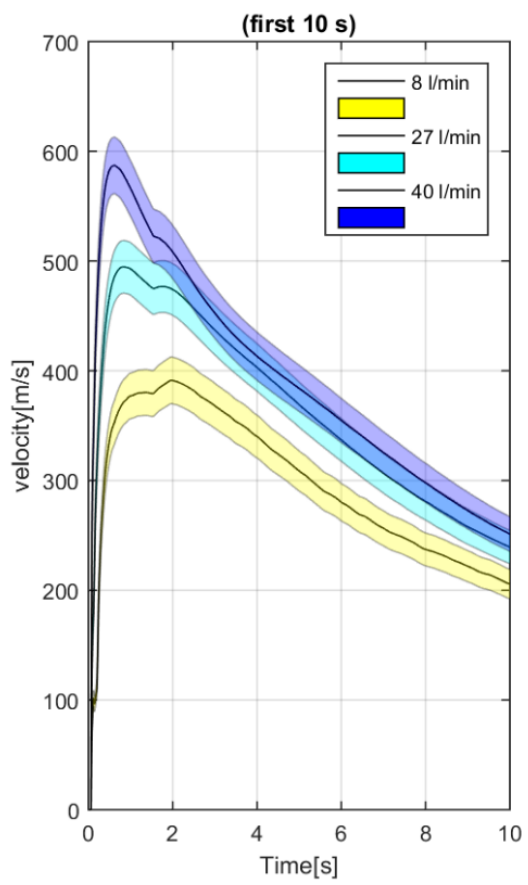

(b)

Figure 11. (a) Description of the velocities variation during the whole experiments. (b) A detail of the velocities variation in the first $10 \mathrm{~s}$.

Figure 12 shows the variation of velocity measure by pressure transducer placed at $1 \mathrm{~cm}$ from valve $\mathrm{D}$ with the air flowed from valve $\mathrm{D}$ at $8 \mathrm{~L} / \mathrm{min}$ (blue diagram), at $27 \mathrm{~L} / \mathrm{min}$ (red diagram) and $40 \mathrm{~L} / \mathrm{min}$ (red diagram) with the related error reference tube.

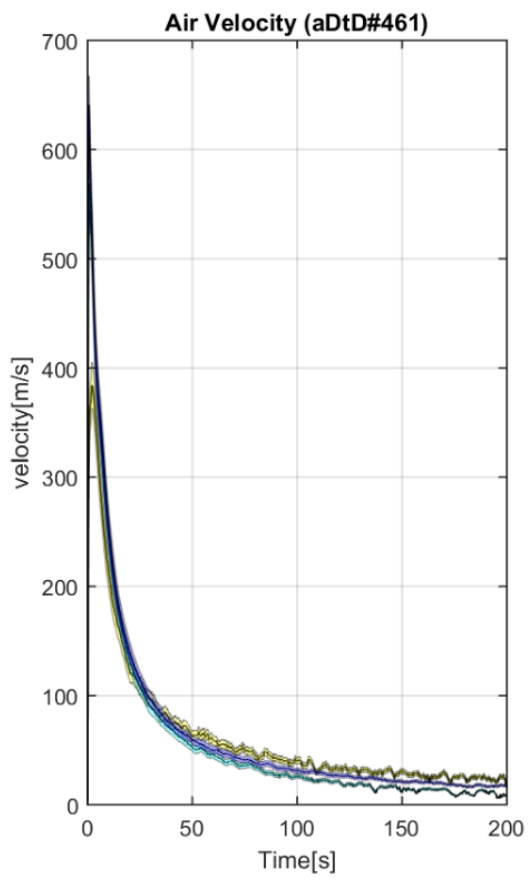

(a)

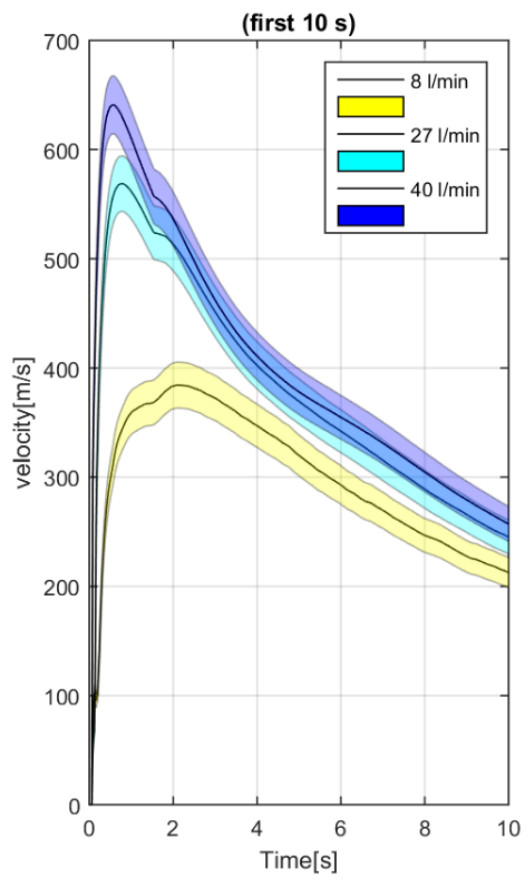

(b)

Figure 12. (a) Description of the velocities variation during the whole experiments. (b) A detail of the velocities variation in the first $10 \mathrm{~s}$. 
"The velocities are evaluated through the transducer \#461 [135]. The trend has a peak for each velocity in the first s, that varies according to the flow rate. It stabilizes in the first $50 \mathrm{~s}$ and then follows an asymptotic behavior that tends to zero."

It is clear from this results that the most important experimental evidence is condensed in the first 5-6 s from the beginning of the accidents (that is the required quantity of time to get mobilized the $90 \%$ of the dust [136-141]).

Experiments from Valve E and F (LOVA Accidents Reproduction)

Figures 13 and 14 shown the variations of internal pressure, temperature and flow rate during the accident replication (with the calculated error bar). The experiments have been conducted only at $27 \mathrm{~L} / \mathrm{min}$ and $40 \mathrm{~L} / \mathrm{min}$ to reproduce the worst condition $(300 \mathrm{~Pa} / \mathrm{s}$ and $500 \mathrm{~Pa} / \mathrm{s})$.

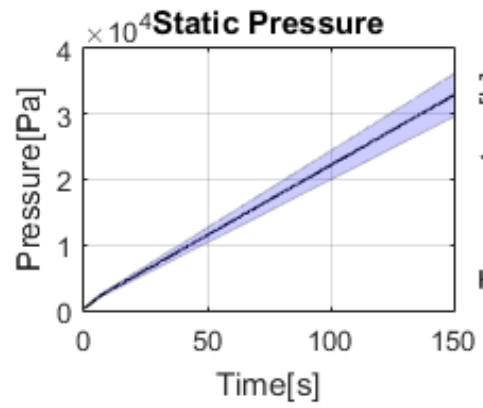

(a)

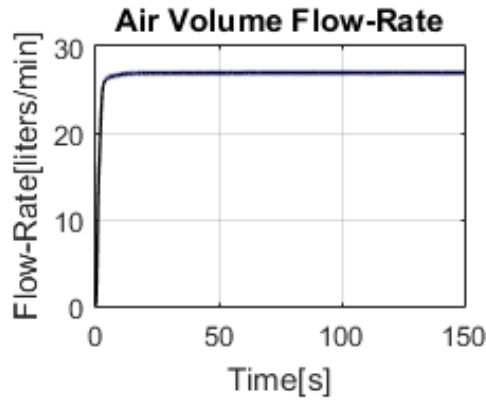

(c)

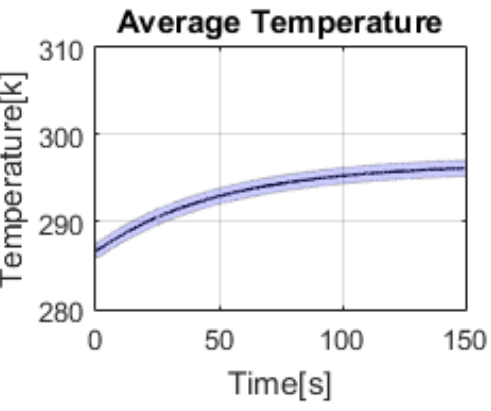

(b)

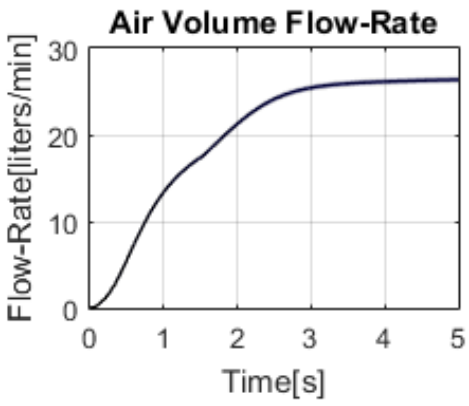

(d)

Figure 13. (a) Description of the pressure increase inside STARDUST-U during the air flow inlet at $27 \mathrm{~L} / \mathrm{min}$. (b) Description of the temperature variations measured during the experiment. (c) Description of the flow rate variation in the time. (d) Flow rate increase in the early stage from the accident experimental simulation.

The results of pressure variations, flow rate variations and temperature variation obtained for vale $\mathrm{F}$ are comparable to those obtained for valve $\mathrm{E}$.

Figure 14 shows velocity with initially growing trend. The peak value is about $200 \mathrm{~m} / \mathrm{s}$ for a flow rate of $40 \mathrm{~L} / \mathrm{min}$ and about $180 \mathrm{~m} / \mathrm{s}$ for a flow rate of $27 \mathrm{~L} / \mathrm{min}$, achieved around $5 \mathrm{~s}$ of the experiment. Then velocity decreased.

Figure 15 shows the variation of velocity measure by pressure transducer placed at 24,5 cm from valve $\mathrm{E}$ with the air flowed from valve $\mathrm{E}$ at $27 \mathrm{~L} / \mathrm{min}$ (red diagram) and $40 \mathrm{~L} / \mathrm{min}$ (blue diagram) with the related error reference tube. 

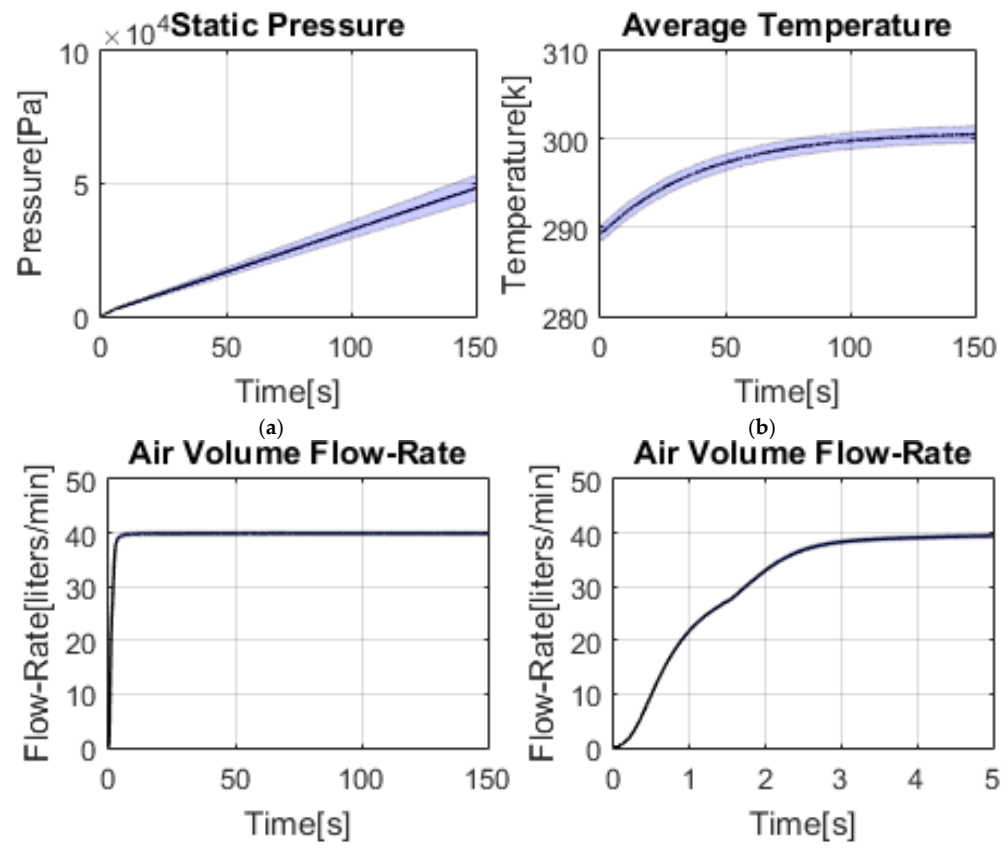

(c)

(d)

Figure 14. (a) Description of the pressure increase inside STARDUST-U during the air flow inlet at $40 \mathrm{~L} / \mathrm{min}$. (b) Description of the temperature variations measured during the experiment. (c) Description of the flow rate variation in the time. (d) Flow rate increase in the early stage from the accident experimental simulation.
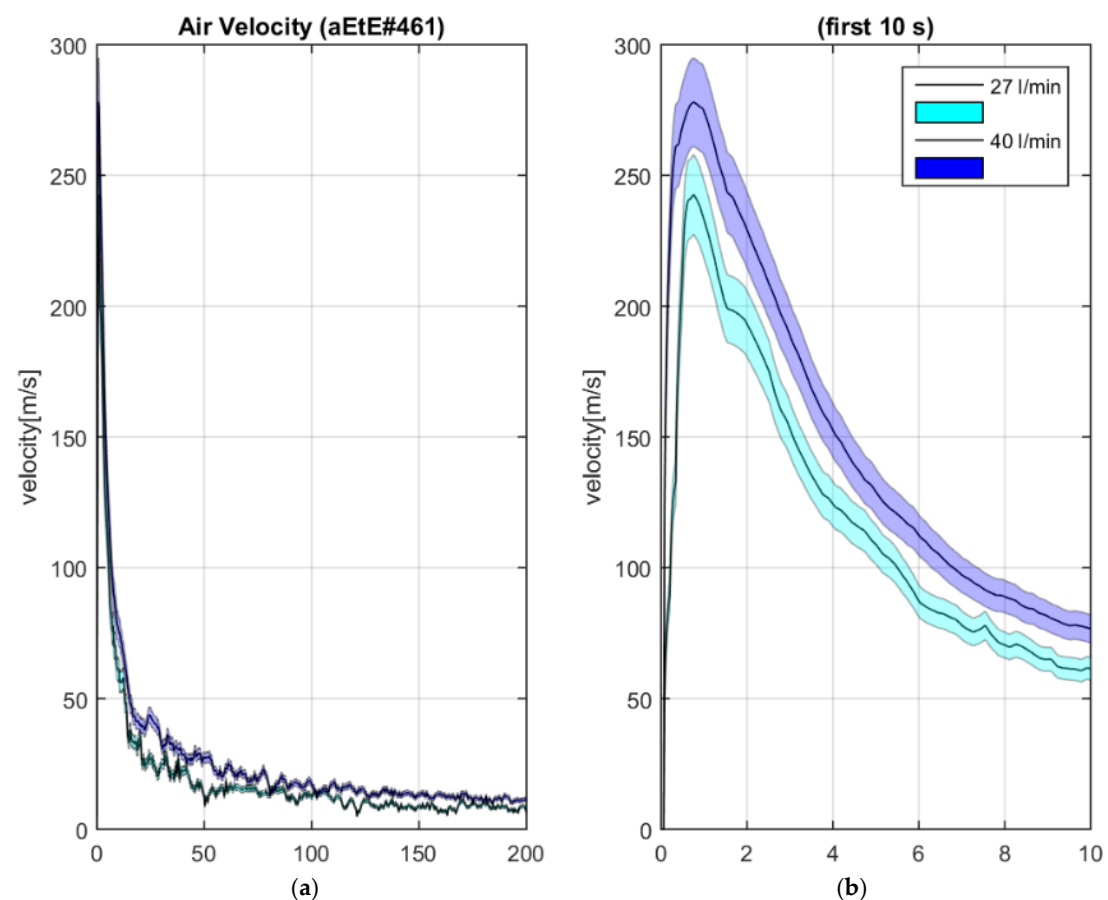

Figure 15. (a) Description of the velocities variation during the whole experiments. (b) A detail of the velocities variation in the first $10 \mathrm{~s}$.

The graphs in Figures 13 and 14 show the internal pressure $(\mathrm{Pa})$, the mean temperature $(\mathrm{K})$ (calculated as arithmetic mean of the temperatures), the flow rate and the flow rate during first $6 \mathrm{~s}$. Graphs include error bars calculated according to error analysis described in "Error Analysis" section. The results showed an increasing monotone linear trends of static pressure, from the initial value fixed 
at $200 \mathrm{~Pa}$ up to the ambient pressure fixed at about $95000 \mathrm{~Pa}$; average temperature trend measured by the thermocouples with almost constant error range of about $2 \mathrm{~K}$; trend of the constant flow rate after approximately $6 \mathrm{~s}$ from the start of the experiment. The trend in the first $\mathrm{s}$ is parabolic and represents that the flow meter takes about $6 \mathrm{~s}$ to open fully.

Figure 15 shows velocity with initially growing trends. The peak value is about $270 \mathrm{~m} / \mathrm{s}$ for a flow rate of $40 \mathrm{~L} / \mathrm{min}$ and about $200 \mathrm{~m} / \mathrm{s}$ for a flow rate of $27 \mathrm{~L} / \mathrm{min}$, achieved around $2 \mathrm{~s}$ of the experiment. After the peak velocity decreased up to asymptotically to zero for different times depending on the flow rate. The graphics have been reported for $10 \mathrm{~s}$ because the first moments are crucial to study the phenomenon of dust mobilization.

Figure 14 shows the variation of velocity measure by pressure transducer placed at $10 \mathrm{~cm}$ from valve $\mathrm{F}$ with the air flowed from valve $\mathrm{F}$ at $27 \mathrm{~L} / \mathrm{min}$ (red diagram) and $40 \mathrm{~L} / \mathrm{min}$ (blue diagram) with the related error reference tube.

Figure 16 shows velocity with an initially growing trend. The peak value is about $200 \mathrm{~m} / \mathrm{s}$ for a flow rate of $40 \mathrm{~L} / \mathrm{min}$ and about $180 \mathrm{~m} / \mathrm{s}$ for a flow rate of $27 \mathrm{~L} / \mathrm{min}$, achieved around $5 \mathrm{~s}$ of the experiment. Then velocity decreased up to asymptotically to zero for different times depending on the flow rate. The graphics have been reported for $10 \mathrm{~s}$ because the first moments are crucial to study the phenomenon of dust mobilization.

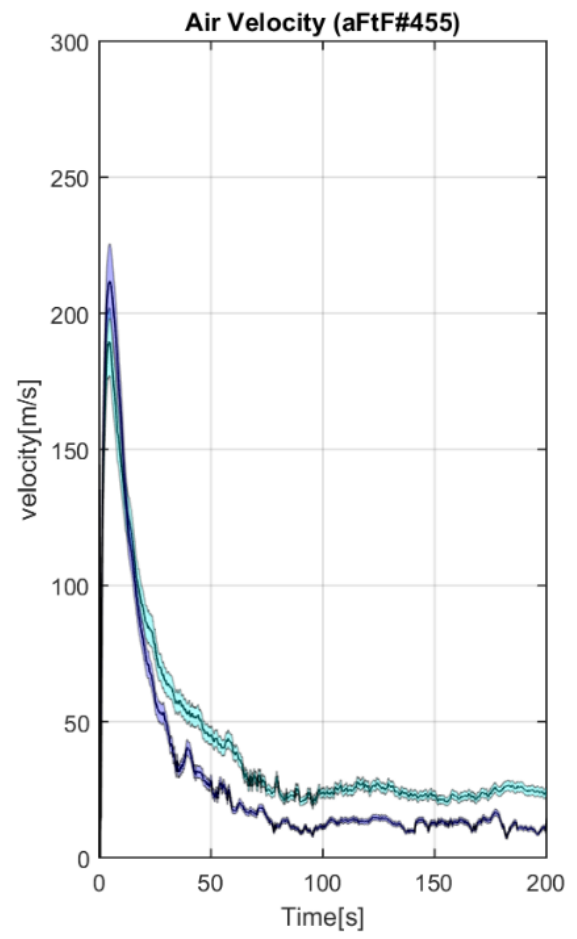

(a)

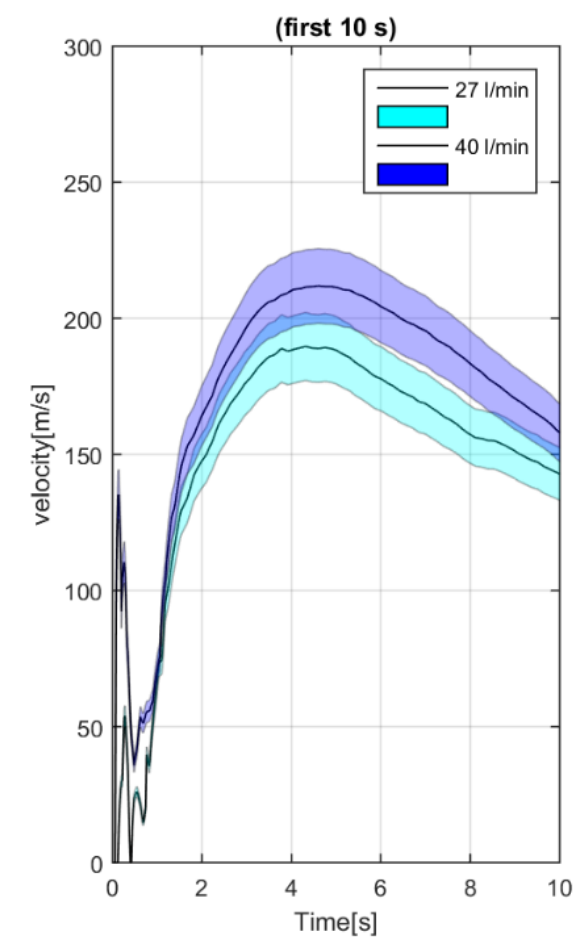

(b)

Figure 16. (a) Description of the velocities variation during the whole experiments. (b) A detail of the velocities variation in the first $10 \mathrm{~s}$.

\subsection{Numerical Simulations}

\subsubsection{Numerical Simulation from Valve C (LOCA Accidents Reproduction)}

The experimental results have been used to carry out the numerical simulations through the software CFX ANSYS 16.0. The flow produced by the entering jet of air leads, as it will be shown, to the formation of several vortices in all configurations. The flow is highly recirculating and the classical $k-\varepsilon$ model has proved not to be fit to this kind of problem. A more accurate model, which takes into account flow separation and recirculation is the SST $k-\omega$. Furthermore, as initially 
the air in the vacuum chamber has a low pressure and therefore a low density, it is expected that in many zones of the vessel where the velocity is low the Reynolds number is low and so the flow is laminar, while is turbulent in elsewhere, so a transitional model, the $\gamma-\theta$ one, has been added to the turbulence model in order to catch the laminar-to-turbulent transition during the opening transient of the valve.

The analysis has been focused on the study the Mach number. The Mach number (Ma) is a dimensionless group that is defined as the ratio between the speed of an object in motion in a fluid and the speed of sound in the considered fluid. It allows to determine how important the compressibility effects of the fluid under examination. "The motion around the bodies can be classified in six different conditions which match to different fluid dynamic behavior.

- $\quad$ Subsonic incompressible regime: $M a<0,2-0,3$

- Subsonic regime: $M a<1$

- Transonic regime: $0,8<M a<1,2$

- Sonic regime: $M a=1$

- $\quad$ Supersonic regime: $M a>1$

- Hypersonic regime: $M a>5$ " [149]

In Figure 17 (port C, $27 \mathrm{~L} / \mathrm{min}$ ), the patterns of Mach number and density are shown on the symmetry plane of the facility at 1s (Figure 17a), 3s (Figure 17b), $6 \mathrm{~s}$ (Figure 17c) and $9 \mathrm{~s}$ (Figure 17d) after the beginning of the pressurization transient:

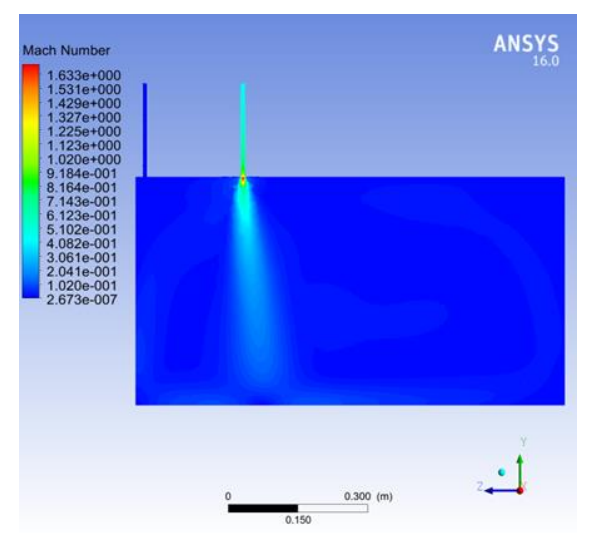

(a)

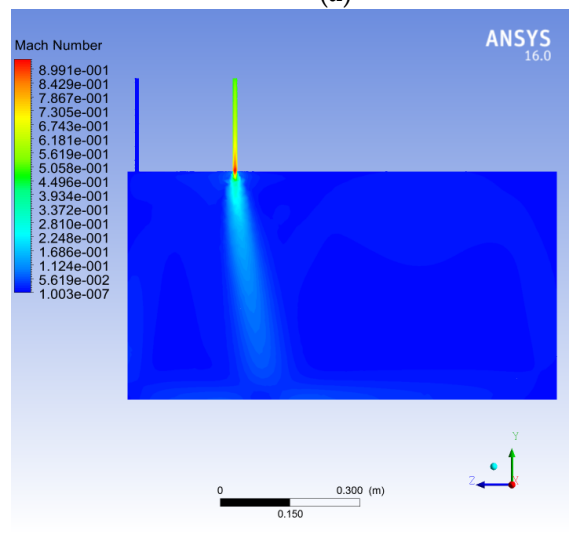

(c)

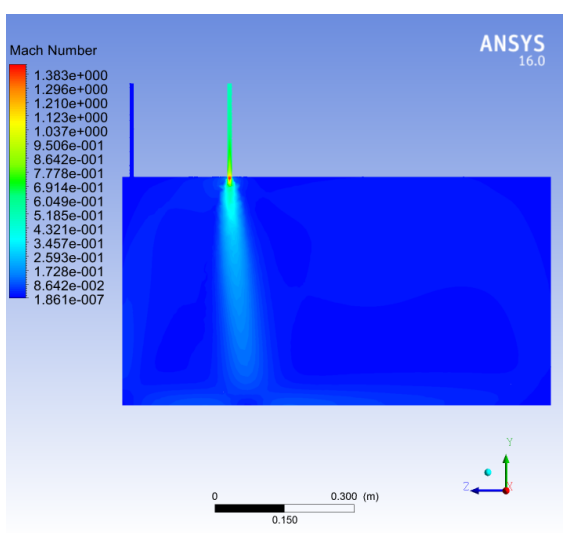

(b)

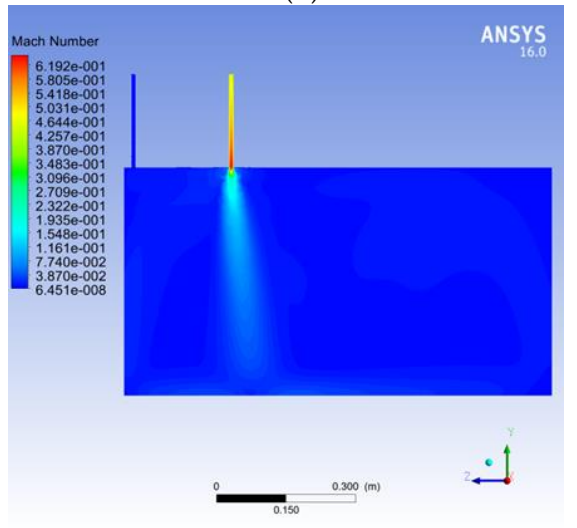

(d)

Figure 17. Air inlet with a flow rate of $27 \mathrm{~L} / \mathrm{min}$, valve $C$ (a) Mach number after $1 \mathrm{~s}$. (b) Mach number after 3 s. (c) Mach number after 6 s. (d) Mach number after $9 \mathrm{~s}$. 
As it can be seen in Figure 17a,b a jet which is always transonic, and even supersonic at some moments, enters in the vacuum vessel. The speed initially increases because the mass flow rate rises, then, as the pressure gets higher, the Mach number drops. The asymmetric position of the inlet port leads to the formation of two counter-rotating vortices whose dimensions are different, as outlined by the density field. The lack of space in the left part of the vacuum chamber makes the jet bend right.

In Figure 18, the graphs of Mach number (a) and pressure (b) are shown for the two mass flow rates in the two probed positions:

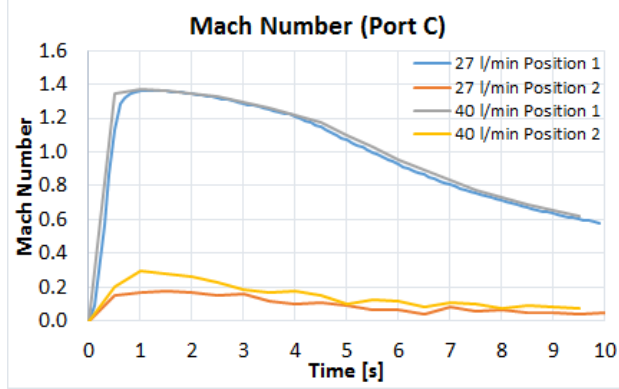

(a)

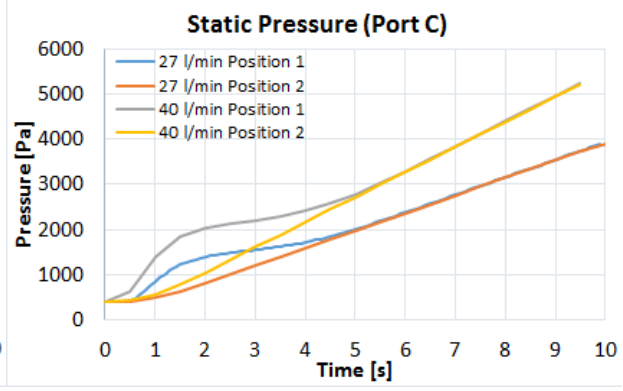

(b)

Figure 18. Mach number (a) and pressure (b) versus time, C port, 27 and $40 \mathrm{~L} / \mathrm{min}$.

In all cases, the Mach number increases initially because of the augmentation of the mass flow rate. Then, as the vessel's pressure and therefore the air density rise, the speed decreases. It can be seen that there is a difference between the Mach number evolution in the two points: in the second one, there are great oscillations, whereas in the first one these fluctuations are not observed. This is due to the fact that two asymmetric and unstable vortices form and make the jet oscillate, which causes rapid variations in the local jet speed. In the first probing point, as the flow is supersonic for several s, the perturbations are not able to move upstream, whereas in the second point, as the flow is subsonic, the influence of the vortices affects the local Mach number.

Both Mach number and pressure rise during time, at a rate which is greater when the mass flow rate is higher. The pressure rises faster near to the inlet than in the second position, due to the lateral dispersion of the jet.

\subsubsection{Numerical Simulation from Valve E and F (LOVA Accidents Reproduction)}

Figure 19 (port E, $27 \mathrm{~L} / \mathrm{min}$ ) show the Mach number and density fields in the symmetry plane containing the inlet duct at 1s (Figure 19a), 3s (Figure 19b), 6 s (Figure 19c) and 9 s (Figure 19d) after the pressurization transient beginning:

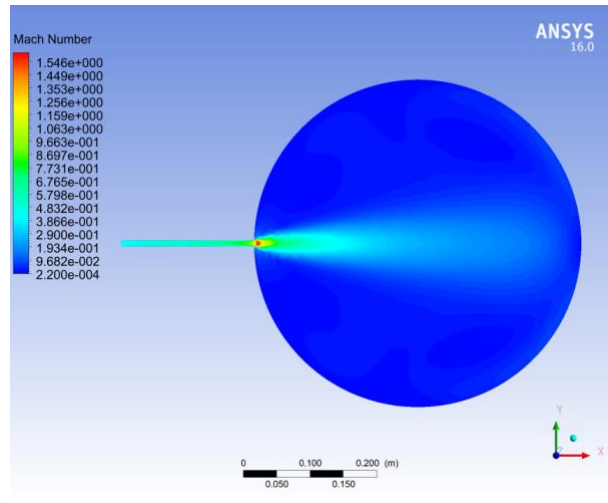

(a)

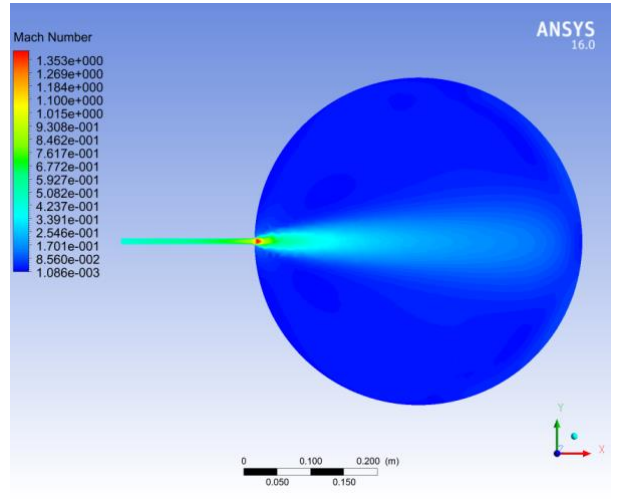

(b)

Figure 19. Cont. 


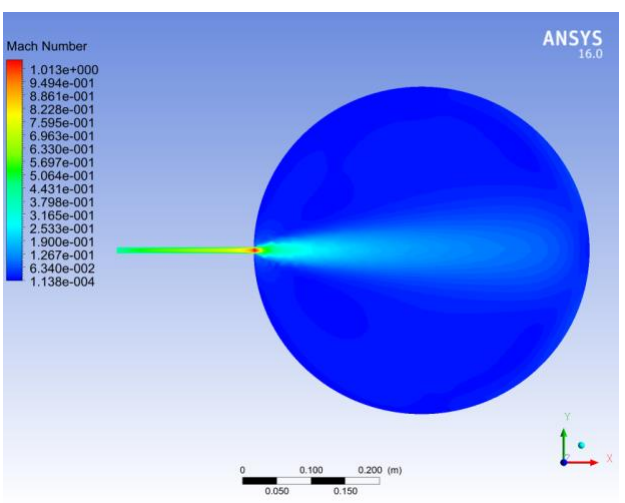

(c)

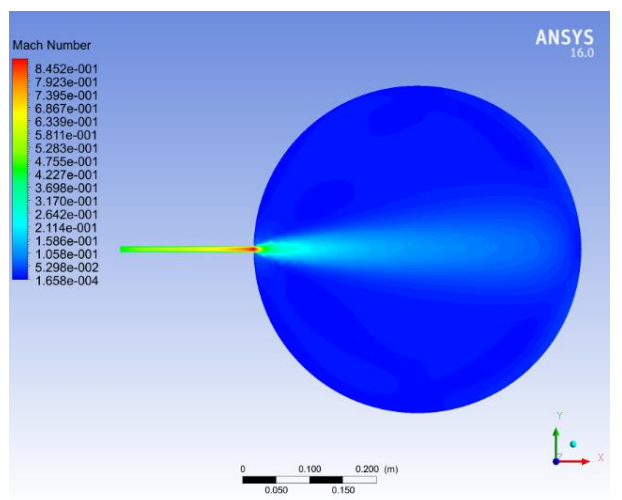

(d)

Figure 19. Air inlet with a flow rate of $27 \mathrm{~L} / \mathrm{min}$, valve $\mathrm{E}$ (a) Mach number after $1 \mathrm{~s}$. (b) Mach number after 3 s. (c) Mach number after 6 s. (d) Mach number after $9 \mathrm{~s}$.

In Figure 20, the Mach number and the pressure evolution during the transient are shown for the two chosen positions:

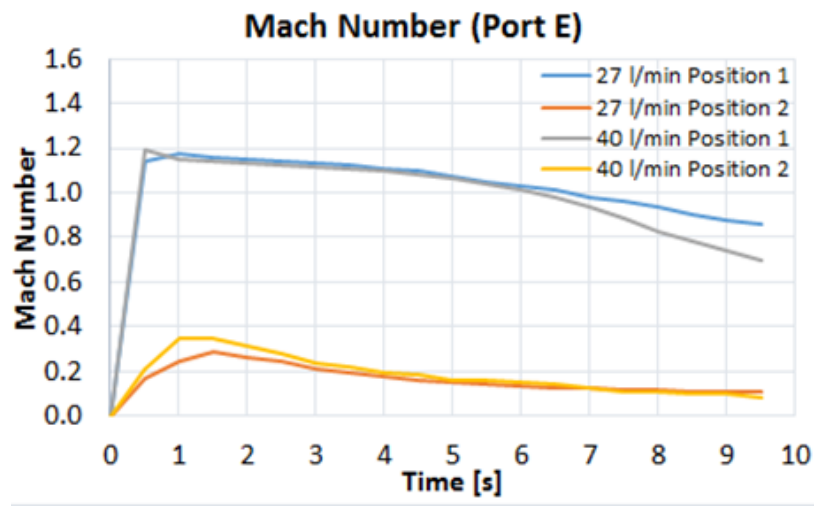

(a)

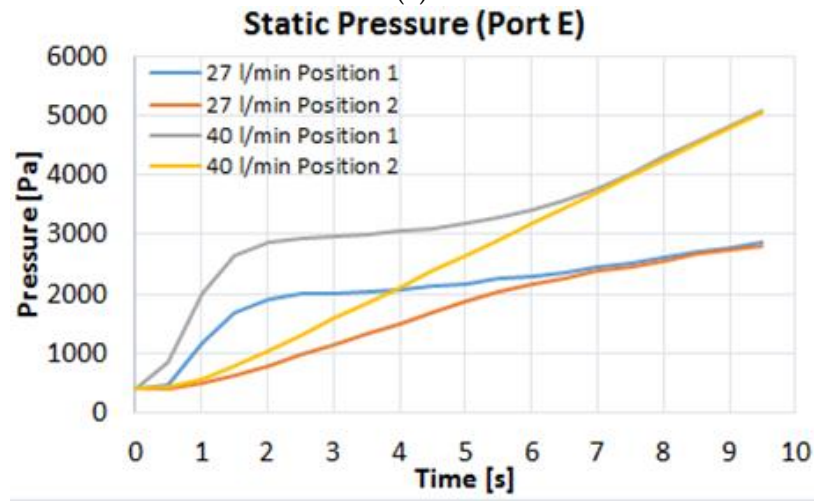

(b)

Figure 20. Mach number (a) and pressure (b) versus time, E port, 27 and $40 \mathrm{~L} / \mathrm{min}$.

In Figure 21 (port F, $27 \mathrm{~L} / \mathrm{min}$ ) show the Mach number and density fields in the symmetry plane containing the inlet duct at 1s (Figure 21a), 3s (Figure 21b), $6 \mathrm{~s}$ (Figure 21c) and $9 \mathrm{~s}$ (Figure 21d) after the pressurisation transient beginning: 


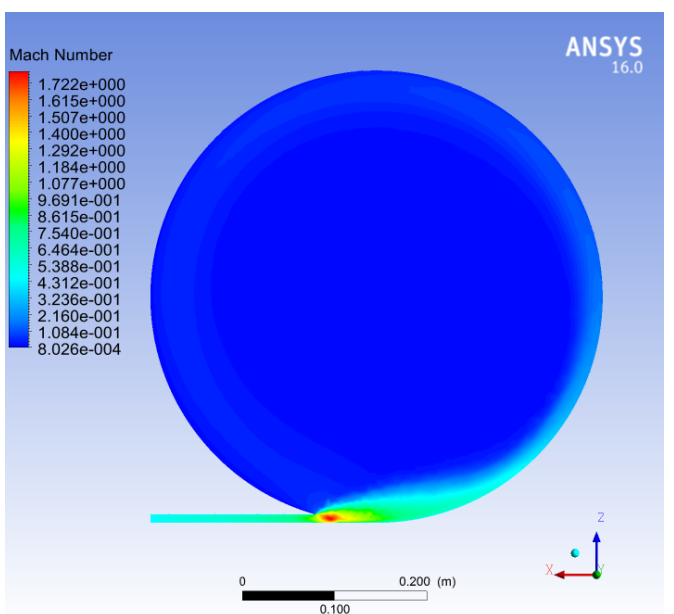

(a)

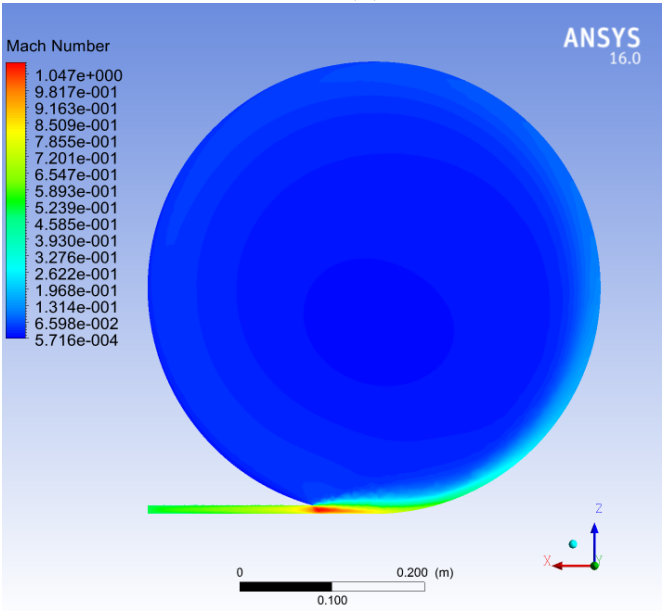

(c)

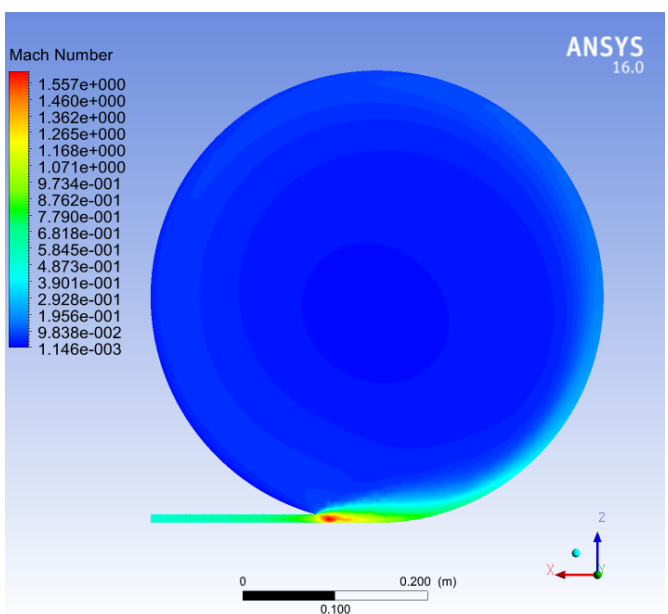

(b)

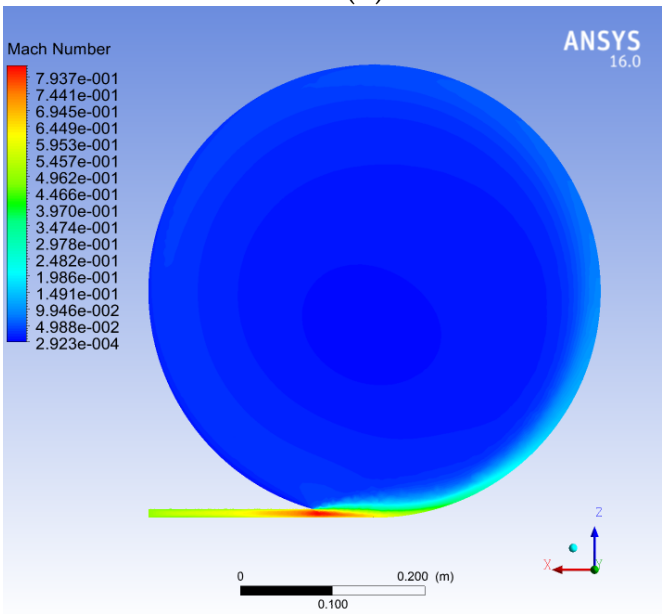

(d)

Figure 21. Mach number, F port, $27 \mathrm{~L} / \mathrm{min}$ valve $\mathrm{E}$ (a) Mach number after $1 \mathrm{~s}$. (b) Mach number after 3 s. (c) Mach number after 6 s. (d) Mach number after 9 s.

Finally, the Mach number and pressure variations with time are shown in Figure 22 for the two probing points:

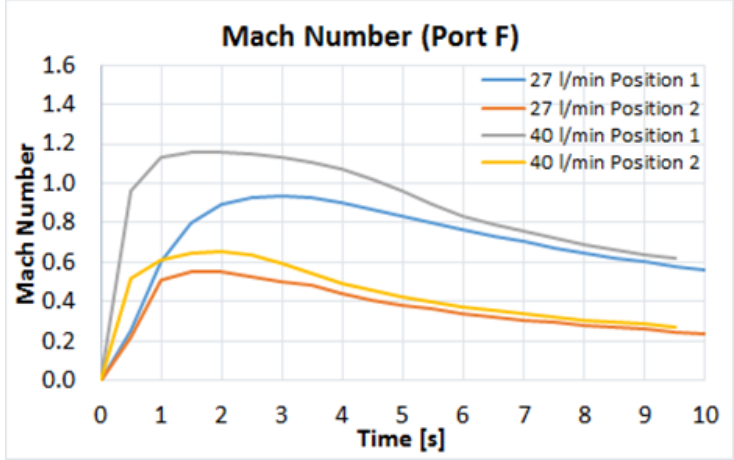

(a)

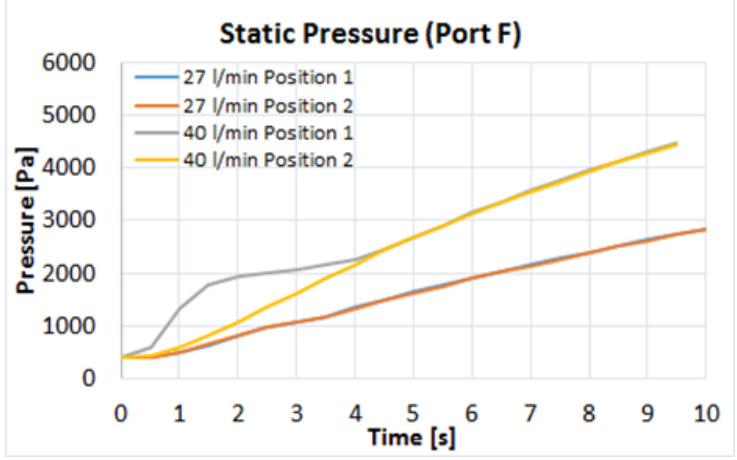

(b)

Figure 22. Mach number (a) and pressure (b) versus time, F port, 27 and $40 \mathrm{~L} / \mathrm{min}$. 
As shown, the Mach number is lower than for the $C$ and $E$ ports, and there are no fluctuations because there is only one stable vortex. For this port, it can be seen that when the flow exiting from the duct is subsonic $(27 \mathrm{~L} / \mathrm{min})$, there is no pressure difference between the two probing points, as they are very close. For the greater mass flow rate $(40 \mathrm{~L} / \mathrm{min})$, the flow just after the duct exit is supersonic and it impacts the curving wall of the vessel. This causes a great loss of pressure, so the pressurization rate is lower in the second probing point than in the first one.

\subsection{Comparison between by Experimental Results and Numerical Simulations}

The experimental results have been compared with the numerical simulation results. This numerical simulation was performed with ANSYS CFX program 16.0. The results obtained experimentally are in agreement with the simulation results. Mach number and static pressure trends obtained with the experimental campaign were compared with that obtained with the numerical simulations. "The Mach number (Ma), equation (1) is a dimensionless group defined as the ratio between the velocity of an object in motion in a fluid and the speed of the sound in the fluid considered.

$$
M a=\frac{\langle v\rangle}{a}=\frac{\langle v\rangle}{\sqrt{\gamma R T}}
$$

where:

$\langle v\rangle:$ macroscopic velocity of the object considered $[\mathrm{m} / \mathrm{s}]$,

a: velocity of sound in the fluid considered $[\mathrm{m} / \mathrm{s}]$,

$\gamma$ : adiabatic coefficient [aim.],

R: specific gas constant [J $\left.\mathrm{kg}^{-1} \mathrm{~K}^{-1}\right]$,

T: absolute temperature [K]." [149]

Figure 23 shows the comparison between the Mach number obtained with the experiments and that calculated numerically. It should be noted that the error tube shown in Figure 23 for the experimental data was calculated according to the error analysis presented below, here uncertainties for all single measurements and indirect errors have been taken into account. In addition, $\langle\mathrm{v}\rangle$ macroscopic velocity of the object considered was calculated according to Equation 2 . This local air velocity is a function of the static pressure of the chamber and the local differential pressure measured by pressure transducers. However, static pressure and differential pressure were measured in two different locations of the chamber (at a distance of about $50 \mathrm{~cm}$ ), due to physical limitations inside the chamber itself. This could have caused, as evidenced in Figure 23 for the higher vacuum level (i.e., the lower initial static pressure of $300 \mathrm{~Pa}$ inside the chamber), that the experimental results appear to reveal an underestimation of the air velocity after about $5 \mathrm{~s}$. In addition, even if it is slightly noticeable from Figure 23 (left hand-side), the gap between numerical and experimental results does not grow after $10 \mathrm{~s}$ and it shrinks down as the air velocity decreases over time. However, the present analysis is focused on the first $5-10 \mathrm{~s}$ of the experiments that are crucial for the dust mobilization phenomena.

It is clear that numerical simulations (performed with ANSYS CFX software) are in substantial agreement with the numerical results. However, the static pressure measured experimentally through Pirani is less than that obtained through the numerical simulations. This is justified by the fact that the static pressure is measured at a pint roughly $50 \mathrm{~cm}$ far from the inlet port where the transducers have been positioned and where is the air inlet valve. Mach number obtained from the velocity during the first $4 \mathrm{~s}$, measured during the experimental campaign, is greater than the velocity measured during the numerical simulation because it is inversely proportional to static pressure. Finally, the maximum experimental Mach number value is in good agreement with the numerical maximum velocity value (see Table 6). The differences between the experimental and numerical results are most likely due to the sensors used (better sensors should be used to this end) as well as to their positioning rather than to the chosen turbulence model. 


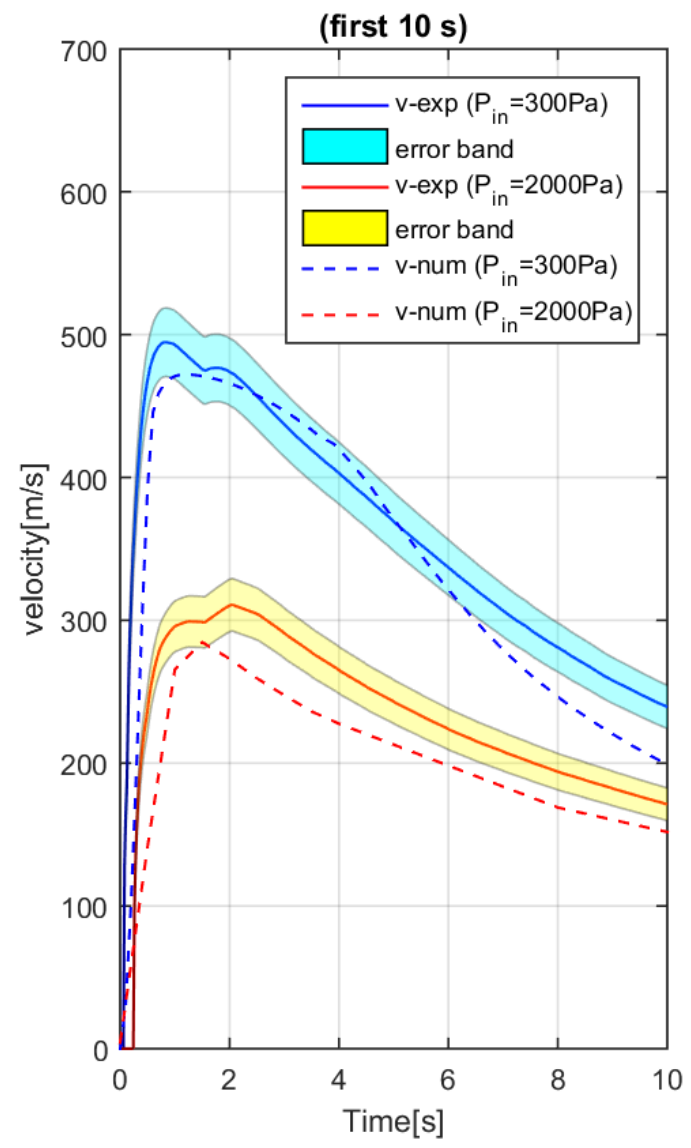

Figure 23. Comparing numerical "numb" and experimental "exp" results for flow rate $27 \mathrm{~L} / \mathrm{min}$, valve $C$, transducers under C, for two different initial vacuum levels "Pin" (300 Pa and $2000 \mathrm{~Pa}$ ).

Table 6. Mach number peak of experimental results and Mach number peak of numerical result, during a simulation of $27 \mathrm{~L} / \mathrm{min}$ flow rate, air from Valve $\mathrm{F}$.

\begin{tabular}{cc}
\hline Data from & Mach Number Peak \\
\hline Numerical simulation & 0.55 \\
Experimental campaign & 0.4 \\
\hline
\end{tabular}

It has to be noted that in terms of relative error on the speed of the flow, the situation is worse in the case of an initial pressure of $300 \mathrm{~Pa}$. This is due to the fact that in this case, the expansion rate of the jet is greater, and therefore there are bigger differences in the pressure measured in two different points. This leads to greater errors in the speed experimental estimation.

Taking account of this error we can see that the experimental results agree with those numerical.

\section{Conclusions}

The objective of this experimental campaign was to determine the air thermos-fluid-dynamic characteristics during accidents of type LOCA and LOVA with the experimental system STARDUST-Upgrade facility. Several replications were made for each experiment. Same boundary conditions have been used:

- $\quad$ initial pressure of $200 \mathrm{~Pa}$;

- final pressure of $95000 \mathrm{~Pa}$;

- $\quad$ room temperature.

- While the following conditions were changed: 
- the flow rate with value of $8 \mathrm{~L} / \mathrm{min}, 27 \mathrm{~L} / \mathrm{min}, 40 \mathrm{~L} / \mathrm{min}$;

- the transducers position: $\mathrm{C}$ and $\mathrm{D}$;

- valve air inlet: $C$ and $D$.

The results evidence a pressure static with a monotonous linear upward trend, from the initial value of $200 \mathrm{~Pa}$ to the environmental pressure of $95000 \mathrm{~Pa}$.

The pressure trends for the three value of flow rate are shown. The blue line is the pressure trend with flow rate of $8 \mathrm{~L} / \mathrm{min}$, the red line is the pressure trend with flow rate of $27 \mathrm{~L} / \mathrm{min}$, while the green line is the pressure trend with flow rate of $40 \mathrm{~L} / \mathrm{min}$. The gradients represent the pressurization rate. It increases with the value of flow rate. This means that the final pressure i.e., the atmospheric pressure is reached at different times for the three flow rate: $1200 \mathrm{~s}$ for flow rate of $8 \mathrm{~L} / \mathrm{min}, 400 \mathrm{~s}$ for flow rate of $27 \mathrm{~L} / \mathrm{min}$ and 250 for flow rate of $40 \mathrm{~L} / \mathrm{min}$.

The mean temperature trend measured by thermocouples is almost constant with an error range of about $2 \mathrm{~K}$. The flow rate reaches a constant trend after about $6 \mathrm{~s}$. The first $6 \mathrm{~s}$ trend is a parabolic type and this time reflects the fact that the flow meter takes time to fully open after signal is received from the control system.

The velocity graphs were developed with MATLAB (see APPENDIX B). All the velocity trends for each replication were similar. The graphs report an increasing velocity trend until a peak. It decreases and stabilizes in the first $50 \mathrm{~s}$ and then follows an asymptotic behaviour that tends to zero.

The peak value of velocity trends in function of the flow rate and the position of transducers are reported:

Air from $C$, transducers under $C$ :

- $\quad$ Time $\cong 2-3 \mathrm{~s} ;$ Velocity $\cong 500 \mathrm{~m} / \mathrm{s}$ flow rate $=40 \mathrm{~L} / \mathrm{min}$;

- $\quad$ Time $\cong 2-3 \mathrm{~s} ;$ Velocity $\cong 470 \mathrm{~m} / \mathrm{s}$ flow rate $=27 \mathrm{~L} / \mathrm{min}$;

- $\quad$ Time $\cong 2-3 \mathrm{~s} ;$ Velocity $\cong 350 \mathrm{~m} / \mathrm{s}$ flow rate $=8 \mathrm{~L} / \mathrm{min}$.

Air from D, transducers under D:

- $\quad$ Time $\cong 2-3 \mathrm{~s} ;$ Velocity $\cong 550 \mathrm{~m} / \mathrm{s}$ flow rate $=40 \mathrm{~L} / \mathrm{min} ;$

- $\quad$ Time $\cong 2-3 \mathrm{~s} ;$ Velocity $\cong 500 \mathrm{~m} / \mathrm{s}$ flow rate $=27 \mathrm{~L} / \mathrm{min}$;

- $\quad$ Time $\cong 2-3 \mathrm{~s} ;$ Velocity $\cong 350 \mathrm{~m} / \mathrm{s}$ flow rate $=8 \mathrm{~L} / \mathrm{min}$.

In the experiments with air from $C$, transducers under $C$, the velocity peak increases of about 20 and $30 \mathrm{~m} / \mathrm{s}$ when the flow rate increases. While in the experiments with air from $\mathrm{D}$, transducers under $D$, the velocity peak increases of about $50 \mathrm{~m} / \mathrm{s}$ when the flow rate increases. The velocity graphs of the first $10 \mathrm{~s}$ are reported because they are crucial for the dust mobilization study. They show another peak before the expected one that is the result of a shock wave caused by the vacuum breach.

So, it was demonstrated that there is a relation between the flow air inlet and the measured velocity: to growing of the first growing the second.

Comparisons with numerical simulation performed with the software ANSYS CFX denote that the experimental results are in agreement with the numerical results.

These data will be useful for the development of a 3D multi-phase numerical model for the study of dust re-suspension and mobilization during the LOCA and LOVA type accidents.

Acknowledgments: A special Acknowledgment goes to Ilaria Giovannangeli and Chiara Del Papa for their efforts in the experimental campaign during their bachelor degrees.

Author Contributions: Andrea Malizia has conducted the work about the state of the art of materials in nuclear fusion plants. Andrea Malizia, Luigi Antonio Poggi and Riccardo Rossi have conducted the experimental campaigns and elaborated the data. Jean Francois Ciparisse, Pasqualino Gaudio and Carlo Bellecci have conducted the numerical simulations.

Conflicts of Interest: The authors declare no conflict of interest. 


\section{References}

1. Nuttall, W.J. Fusion as an Energy Source; Institute of Physics: London, UK, 2008. Available online: https://www.iop.org/publications/iop/2008/file_38224.pdf (accessed on 18 April 2016).

2. European Commission. Fusion Research an Energy Option for Europe's Future; Office for Official Publications of the European Communities: Luxembourg, 2007. Available online: https://ec.europa.eu/research/energy/ pdf/92-79-00513-8_en.pdf (accessed on 18 April 2016).

3. Redd, N.T. What is Fusion? 2012. Available online: http://www.livescience.com/23394-fusion.html (accessed on 19 July 2016).

4. Brumfiel, G. Fusion Dreams Delayed-Nature. Available online: http://www.nature.com/news/2009/ 090527/full/459488a.html (accessed on 20 July 2016).

5. Sharpe, J.P.; Petti, D.A.; Bartels, H.W. A review of dust in fusion devices: Implications for safety and operational performance. Fusion Eng. Des. 2002, 63-64, 153-163. [CrossRef]

6. Winter, J. Dust: A new challenge in nuclear fusion research? Phys. Plasmas 2002, 7, 3862-3866. [CrossRef]

7. Malizia, A.; Lupelli, I.; Richetta, M.; Gelfusa, M.; Bellecci, C.; Gaudio, P. Safety Analysis in Large Volume Vacuum Systems Like Tokamak: Experiments and Numerical Simulation to Analyse Vacuum Ruptures Consequences. Adv. Mater. Sci. Eng. 2014, 2014, 1-29. [CrossRef]

8. Federici, G.; Skinner, C.H.; Brooks, J.N.; Coad, J.P.; Grisolia, C.; Haasz, A.A.; Hassanein, A.; Philipps, V.; Pitcher, C.S.; Roth, J.; et al. Plasma-material interactions in current tokamaks and their implications for next step fusion reactors. Nucl. Fusion 2001, 41, 1967-2137. [CrossRef]

9. Federici, G.; Andrew, P.; Barabaschi, P.; Brooks, J.; Doerner, R.; Geier, A.; Herrmann, A.; Janeschitz, G.; Krieger, K.; Kukushkin, A.; et al. Key ITER plasma edge and plasma-material interaction issues. J. Nucl. Mater. 2003, 313-316, 11-22. [CrossRef]

10. ITER. Radiological and Energy Source Terms. Generic Site Safety Report, Vol. III, G 84 RI 3 01-07-13 R1.0 Garching JWS. 2001. Available online: https://fusion.gat.com/iter/iter-fdr/final-report-sep-2001/Plant_ Assembly_Documents_(PADs)/Generic_Site_Safety_Report_GSSR/GSSR_03_Rad+EnergySources.pdf (accessed on 18 April 2016).

11. Jin, X.Z.; Bachmann, C.; Porfiri, M.T.; Federici, G. Source terms and critical event sequences for the blanket concept HCPB. Report for Task Agreement, EFDA_D_2L8RZY v3.0-WP13-SYS04-T03. 2014. Available online: https:/ /idm.euro-fusion.org/?uid=2L8RZY (accessed on 18 April 2016).

12. Jin, X.Z.; Bachmann, C.; Porfiri, M.T.; Federici, G. Source terms and critical event sequences for two DEMO blanket concepts HCPB and HCLL. Report for Task Agreement, EFDA_D_2LDAL4 V2.0-WP13-SYS04-T03. 2014. Available online: https://idm.euro-fusion.org/?uid=2KX64M (accessed on 18 April 2016).

13. Di Giovanni, D.; Luttazzi, E.; Marchi, F.; Latini, G.; Carestia, M.; Malizia, A.; Gelfusa, M.; Fiorito, R.; D'Amico, F.; Cenciarelli, O.; et al. Two realistic scenarios of intentional release of radionuclides (Cs-137, Sr-90)-The use of the HotSpot code to forecast contamination extent. WSEAS Trans. Environ. Dev. 2014, 10, 106-122.

14. Malizia, A.; Lupelli, I.; D’Amico, F.; Sassolini, A.; Fiduccia, A.; Quarta, A.M.; Fiorito, R.; Gucciardino, A.; Richetta, M.; Bellecci, C.; et al. Characterisation of Carbon Dioxide Absorbent Material For Enclosed Space Applications. Def. S T Tech. Bull. 2012, 5, 36-45.

15. Rondeau, A.; Merrison, J.; Iversen, J.J.; Peillon, S.; Sabroux, J.C.; Lemaitre, P.; Gensdarmes, F.; Chassefière, E. First experimental results of particle re-suspension in a low pressure wind tunnel applied to the issue of dust in fusion reactors. Fusion Eng. Des. 2015, 32, 98-99. [CrossRef]

16. Sharpe, J.P.; Humrickhouse, P.W. Dust mobilization studies in the TDMX facility. Fusion Eng. Des. 2006, 81, 1409-1415. [CrossRef]

17. Baluc, N.; Abe, K.; Boutard, J.L.; Chernov, V.M.; Diegele, E.; Jitsukawa, S.; Kimura, A.; Klueh, R.L.; Kohyama, A.; Kurtz, R.J.; et al. Status of R\&D activities on materials for fusion power reactors. Nucl. Fusion 2007, 47, S696-S717.

18. Stork, D.; Agostini, P.; Boutard, J.-L.; Buckthorpe, D.; Diegele, E.; Dudarev, S.L.; English, C.; Federici, G.; Gilbert, M.R.; Gonzalez, S.; et al. Materials R\&D for a timely DEMO: Key findings and recommendations of the EU Roadmap Materials Assessment Group. Fusion Eng. Des. 2014, 89, 1586-1594. 
19. Boccaccini, L.V.; Hermsmeyer, S.; Fischer, U.; Ihli, T.; Janeschitz, G.; Kohly, C.; Nagy, D.; Norajitra, P.; Polixa, C.; Reinamnn, J.; et al. Studies of In-Vessel Component Integration for a Helium-Cooled Fusion Reactor. Available online: http://www-pub.iaea.org/MTCD/publications/PDF/P1250-cd/papers/ppca1-i.pdf (accessed on 18 July 2016).

20. Kakudate, S.; Shibanuma, K. Rail deployment and storage procedure and test for ITER blanket remote maintenance. Fusion Eng. Des. 2003, 65, 133-140. [CrossRef]

21. Raffray, A.R.; Chiocchio, S.; Ioki, K.; Krassovski, D.; Kubik, D.; Tivey, R. High heat flux thermal-hydraulic analysis of ITER divertor and blanket systems. Fusion End. Des. 1998, 39-40, 323-331. [CrossRef]

22. Izard, J.B. Development of Remote Handling Technologies Tolerant to Operation Ready Fusion Reactor Conditions. Ph.D. Thesis, Tampere University of Technology, Tampere, Finland, 14 June 2013.

23. Kallenbach, A.; Kaufmann, M.; Coster, D.P.; Fuchs, J.C.; Herrmann, A.; Neuhauser, J.; Schneider, R.; Borrass, K.; Bosch, H.-S.; Carlson, A.; et al. Scrape-off layer radiation and heat load to the ASDEX Upgrade LYRA divertor. Nucl. Fusion 1999, 39, 901-918. [CrossRef]

24. Loarte, A.; Lipschultz, B.; Kukushkin, A.S.; Matthews, G.F.; Stangeby, P.C.; Asakura, N.; Cousnell, G.F.; Federici, G.; Kallenbach, A.; Kneger, K.; et al. Chapter 4: Power and particle control. In Nuclear Fusion; IAEA: Vienna, Austria, 2007; Volume 47.

25. Loarte, A.; Saibene, G.; Sartori, R.; Riccardo, V.; Andrew, P.; Paley, J.; Fundamenski, W.; Eich, T.; Herrmann, A.; Pautasso, G.; et al. Transient heat loads in current fusion experiments, extrapolation to ITER and consequences for its operation. Phys. Scr. 2007, 2007, 222-228. [CrossRef]

26. Hender, T.C. Chapter 3: MHD stability, operational limits and disruptions. In Nuclear Fusion; IAEA: Vienna, Austria, 2007; Volume 47.

27. Roth, J.; Preuss, R.; Bohmeyer, W.; Brezinsek, S.; Cambe, A.; Casarotto, E.; Doerner, R.; Gauthier, E.; Federici, G.; Higashijima, S.; et al. Flux dependence of carbon chemical erosion by deuterium ions. Nucl. Fusion 2004, 44, L21-L25. [CrossRef]

28. Longhurst, G.R.; Snead, L.L.; Abou-Sena, A.A. The status of beryllium research for fusion in the United States. In Proceedings of the Sixth International Workshop on Beryllium-Technology for Fusion, Miyazaki, Japan, 2 December 2003.

29. Thomas, P.R.; Jet Team. Results of JET operation with beryllium. J. Nucl. Mater. 1990, 176-177, 3-13.

30. Campbell, D.J.; Jet Team. Experimental comparison of carbon and beryllium as divertor target materials in JET. J. Nucl. Mater. 1997, 241-243, 379-384. [CrossRef]

31. Anderl, R.A.; Causey, R.A.; Davis, J.W.; Doerner, R.P.; Federici, G.; Haasz, A.A.; Longhurst, G.; Wampler, W.R.; Wilson, K.L. Hydrogen isotope retention in beryllium for tokamak plasma-facing applications. J. Nucl. Mater. 1999, 273, 1-26. [CrossRef]

32. Causey, R.A. Hydrogen isotope retention and recycling in fusion reactor plasma-facing components. J. Nucl. Mater. 2002, 300, 91-117. [CrossRef]

33. Mayer, M. Codeposition of deuterium with BeO at elevated temperatures. J. Nucl. Mater. 1997, 240, $164-167$. [CrossRef]

34. Doerner, R.P.; Baldwin, M.J.; Causey, R.A. Beryllium-tungsten mixed-material interactions. J. Nucl. Mater. 2005, 342, 63-67. [CrossRef]

35. Doerner, R.P.; Baldwin, M.J.; Conn, R.W.; Grossman, A.A.; Luckhardt, S.C.; Seraydarian, R.; Tynan, G.R.; Whyte, D.G. Measurements of erosion mechanisms from solid and liquid materials in PISCES-B. J. Nucl. Mater. 2001, 290-293, 166-172. [CrossRef]

36. Doerner, R.P.; Krasheninnikov, S.I.; Schmid, K. Particle-induced erosion of materials at elevated temperature. J. Appl. Phys. 2004, 95, 4471. [CrossRef]

37. Piet, S.J.; Costley, A.; Federici, G.; Heckendorn, F.; Little, R. ITER tokamak dust-limits, production, removal, surveying. In Proceedings of the 17th IEEE/NPSS Symposium on Fusion Engineering, San Diego, CA, USA, 6-10 October 1997.

38. Whyte, D.G.; Davis, J.W. Tritium recovery in ITER by radiative plasma terminations. J. Nucl. Mater. 2005, 337-339, 560-564. [CrossRef]

39. Loarte, A.; Saibene, G.; Sartori, R.; Campbell, D.J.; Lomas, P.J.; Matthews, G.F. A new look at JET operation with Be as plasma facing material. J. Nucl. Mater. 2005, 337-339, 816-820. [CrossRef]

40. Lingertat, J.; Tabasso, A.; Ali-Arshad, S.; Alper, B.; van Belle, P.; Borrass, K.; Clement, S.; Coad, J.P.; Monk, R. Studies of giant ELM interaction with the divertor target in JET. J. Nucl. Mater. 1997, 241-243, 402-407. 
41. Ciotti, M.; Ferro, C.; Maddaluno, G. Optimization of the FTU toroidal limiter shape. J. Nucl. Mater. 1992, 196-198, 725-728. [CrossRef]

42. Hutchinson, I.H.; Boivin, R.; Bombarda, F.; Bonoli, P.; Fairfax, S.; Fiore, C.; Goetz, J.; Golovato, S.; Granetz, R.; Greenwald, M.; et al. First results from Alcator-C-MOD. Phys. Plasmas 1994, 1, 1511-1518. [CrossRef]

43. Pospieszczyk, A.; Tanabe, T.; Philipps, V.; Sergienko, G.; Ohgo, T.; Kondo, K.; Wada, M.; Rubel, M.; Biel, W.; Kirschner, A.; et al. Operation of TEXTOR-94 with tungsten poloidal main limiters. J. Nucl. Mater. 2001, 290-293, 947-952. [CrossRef]

44. Neu, R.; Dux, R.; Geier, A.; Kallenbach, A.; Pugno, R.; Rohde, V.; Bolshukhin, D.; Fuchs, J.C.; Gehre, O.; Gruber, O.; et al. Impurity behaviour in the ASDEX Upgrade divertor tokamak with large area tungsten walls. Plasma Phys. Control. Fusion 2002, 44, 811-826. [CrossRef]

45. Neu, R.; Bobkov, V.; Dux, R.; Fuchs, J.C.; Gruber, O.; Herrmann, A.; Kallenbach, A.; Maier, H.; Mayer, M.; Putterich, T.; et al. Ten years of W programme in ASDEX Upgrade-Challenges and conclusions. Phys. Scr. 2009, T138, 014038. [CrossRef]

46. May, M.J.; Fournier, K.B.; Goetz, J.A.; Terry, J.L.; Pacella, D.; Finkenthal, M.; Marmar, E.S.; Goldstein, W.H. Intrinsic molybdenum impurity density and radiative power losses with their scalings in ohmically and ICRF heated Alcator C-Mod and FTU tokamak plasmas. Plasma Phys. Control. Fusion 1998, 41, 45-64. [CrossRef]

47. Lipschultz, B.; Pappas, D.A.; LaBombard, B.; Rice, J.E.; Smith, D.; Wukitch, S.J. A study of molybdenum influxes and transport in Alcator C-Mod. Nucl. Fusion 2001, 41, 585-596. [CrossRef]

48. Apicella, M.L.; Mazzitelli, G.; Apruzzese, G.; Bracco, G.; Esposito, B.; Gabellieri, L.; Kroegler, H.; Leigheb, M.; Maddaluno, G.; Marinucci, M.; et al. Effects of wall boron coating on FTU plasma operations. J. Nucl. Mater. 2003, 313-316, 269-273. [CrossRef]

49. Rieth, M.; Dudarev, S.L.; Gonzalez de Cicente, S.M.; Aktaa, J.; Ahlgren, T.; Antusch, S.; Armstrong, D.E.J.; Balden, M.; Baluc, N.; Barthe, M.F.; et al. Recent progress in research on tungsten materials for nuclear fusion applications in Europe. J. Nucl. Mater. 2013, 432, 482-500. [CrossRef]

50. Rieth, M.; Dudarev, S.L.; Gonzalez de Vicente, S.M.; Aktaa, J.; Ahlgren, T.; Antusch, S.; Armstrong, D.E.J.; Balden, M.; Baluc, N.; Barthe, M.F.; et al. A brief summary of the progress on the EFDA tungsten materials program. J. Nucl. Mater. 2013, 442, S173-S180. [CrossRef]

51. Pamela, J.; Bécoulet, A.; Borba, D.; Boutard, J.L.; Horton, L.; Maisonnier, D. Efficiency and availability driven R\&D issues for DEMO. Fusion Eng. Des. 2009, 84, 194-204.

52. Maisonnier, D.; Campbell, D.; Cook, I.; Di Pace, L.; Giancarli, L.; Hayward, J.; Li Puma, A.; Medrano, M.; Norajitra, P.; Roccella, M.; et al. Power plant conceptual studies in Europe. Nucl. Fusion 2007, 47, 1524-1532. [CrossRef]

53. Norajitra, P.; Abdel-Khalik, S.I.; Giancarli, L.M.; Ihli, T.; Janeschitz, G.; Malang, S.; Mazul, I.V.; Sardain, P. Divertor conceptual designs for a fusion power plant. Fusion Eng. Des. 2008, 83, 893-902. [CrossRef]

54. Janeschitz, G. Plasma-wall interaction issues in ITER. J. Nucl. Mater. 2001, 290-293, 1-11. [CrossRef]

55. Bolt, H.; Barabash, V.; Federici, G.; Linke, J.; Loarte, A.; Roth, J.; Sato, K. Plasma facing and high heat flux materials-needs for ITER and beyond. J. Nucl. Mater. 2002, 307-311, 43-52. [CrossRef]

56. Wittlich, K.; Hirai, T.; Compan, J.; Klimov, N.; Linke, J.; Loarte, A.; Merola, M.; Pintsuk, G.; Podkovyrov, V.; Singheiser, L.; Zhitlukhin, A. Damage structure in divertor armor materials exposed to multiple ITER relevant ELM loads. Fusion Eng. Des. 2009, 84, 1982-1986. [CrossRef]

57. Hirai, T.; Pintsuk, G.; Linke, J.; Batilliot, M. Cracking failure study of ITER-reference tungsten grade under single pulse thermal shock loads at elevated temperatures. J. Nucl. Mater. 2009, 390-391, 751-754. [CrossRef]

58. Roth, J.; Tsitrone, E.; Loarte, A.; Loarer, Th.; Counsell, G.; Neu, R.; Philipps, V.; Brezinsek, S.; Lehnen, M.; Coad, P.; et al. Recent analysis of key plasma wall interactions issues for ITER. J. Nucl. Mater. 2009, 390-391, 1-9. [CrossRef]

59. Rieth, M.; Boutard, J.L.; Dudarev, S.L.; Ahlgren, T.; Antusch, S.; Baluc, N.; Barthe, M.F.; Becquart, C.S.; Ciupinski, L.; Correia, J.B.; et al. Review on the EFDA programme on tungsten materials technology and science. J. Nucl. Mater. 2011, 417-463, 463-467. [CrossRef]

60. Rieth, M.; Hoffmann, A. Influence of microstructure and notch fabrication on impact bending properties of tungsten materials. Int. J. Refract. Met. Hard Mater. 2010, 28, 679-686. [CrossRef]

61. Nemoto, Y.; Hasegawa, A.; Satou, M.; Abe, K.; Hiraoka, Y. Microstructural development and radiation hardening of neutron irradiated Mo-Re alloys. J. Nucl. Mater. 2004, 324, 62-70. [CrossRef] 
62. Duwe, R.; Kühnlein, W.; Münstermann, M. The new electron beam facility for materials testing in hot cells-Design and Preliminary experience. In Proceedings of the 18th Symposium on Fusion Technology, Karlsruhe, Germany, 22-26 August 1994.

63. Greuner, H.; Bolt, H.; Böswirth, B.; Lindig, S.; Kuhnlein, W.; Huber, T.; Sato, K.; Suzuki, S. Vacuum plasma-sprayed tungsten on EUROFER and 316L: Results of characterisation and thermal loading tests. Fusion Eng. Des. 2005, 75, 333-338. [CrossRef]

64. Maisonnier, D.; Cook, I.; Sardain, P.; Andreani, R.; Di Pace, L.; Forrest, R.; Giancarli, L.; Hermsmeyer, S.; Norajitra, P.; Taylor, N.; Ward, D. A Conceptual Study of Commercial Fusion Power Plants; Final Report of the European Fusion Power Plant Conceptual Study (PPCS). EFDA, 2005. Available online: https:/ / www.ipp.mpg. de/ippcms/de/presse/archiv/PPCS_summary (accessed on 18 April 2016).

65. Koch, F.; Bolt, H. Self passivating W-based alloys as plasma facing material for nuclear fusion. Phys. Scr. 2007, T128, 100-105. [CrossRef]

66. Koch, F.; Köppl, S.; Bolt, H. Self passivating W-based alloys as plasma-facing materiatungsten 1. J. Nucl. Mater. 2009, 386-388, 572-574.

67. Koch, F.; Brinkmann, J.; Lindig, S.; Mishra, T.P.; Linsmeier, C. Oxidation behaviour of silicon-free tungsten alloys for use as first wall material. Phys. Scr. 2011, T145, 014019. [CrossRef]

68. López-Ruiz, P.; Ordás, N.; Lindig, S.; Koch, F.; Iturriza, I.; García-Rosales, C. Self passivating bulk tungsten-based alloys manufactured by powder metallurgy. Phys. Scr. 2011, T145, 014018.

69. Gonzalez, C.; Panizo-Laiz, M.; Gordillo, N.; Guerrero, C.L.; Tejado, E.; Munnik, F.; Piaggi, P.; Bringa, E.; Iglesias, R.; Gonzalez-Arrabal, R. H trapping and mobility in nanostructured tungsten grain boundaries: A combined experimental and theoretical approach. Nucl. Fusion, 2015, 55, 11. [CrossRef]

70. López-Ruiz, P.; Ordás, N.; Iturriza, I.; Koch, F.; García-Rosales, C. Powder metallurgical processing of self-passivating tungsten alloys for fusion first wall application. J. Nucl. Mater. 2013, 442, S219-S224. [CrossRef]

71. Neu, R.; Dux, R.; Kallenbach, A.; Putterich, T.; Balden, M.; Fuchs, J.C.; Herrmann, A.; Maggi, C.F.; O'Mullane, M.; Pugno, R.; et al. Tungsten: an option for divertor and main chamber plasma facing components in future fusion devices. Nucl. Fusion 2005, 45, 209-218. [CrossRef]

72. Matějíček, J.; Chráska, P.; Linke, J. Thermal spray coatings for fusion applications-Review. J. Therm. Spray Technol. 2007, 16, 64-83. [CrossRef]

73. Davis, J.W.; Slattery, K.T.; Driemeyer, D.E.; Ulrickson, M.A. Use of tungsten coatings on ITER plasma facing components. J. Nucl. Mater. 1996, 233-237, 604-608. [CrossRef]

74. Bloom, E.E. The challenge of developing structural materials for fusion power systems. J. Nucl. Mater. 1998, 258-263, 7-17. [CrossRef]

75. Ehrlich, K.; Bloom, E.E.; Kondo, T. International strategy for fusion materials development. J. Nucl. Mater. 2001, 283-287, 79-88. [CrossRef]

76. Zinkle, S.J.; Victoria, M.; Abe, K. Scientific and engineering advances from fusion materials R\&D. J. Nucl. Mater. 2002, 307-311, 31-42.

77. Bloom, E.E.; Conn, R.W.; Davis, J.W.; Gold, R.E.; Little, R.; Schultz, K.R.; Smith, D.L.; Wiffen, F.W. Low Activation Materials for fUsion Applications. University of California-Los Angeles (UCLA), UCLA Report PPG-728, 1983. Available online: http://dx.doi.org/10.1016/0022-3115(84)90570-1 (accessed on 18 April 2016).

78. Mansur, L.K.; Rowcliffe, A.F.; Nanstad, R.K.; Zinkle, S.J.; Corwin, W.R.; Stoller, R.E. Materials needs for fusion, Generation IV fission reactors and spallation neutron sources-Similarities and differences. J. Nucl. Mater. 2004, 329-333, 166-172. [CrossRef]

79. Klueh, R.L. Ferritic/martensitic steels for advanced nuclear reactors. Trans. Indian Inst. Met. 2009, 62, 81-87. [CrossRef]

80. Mansur, L.K. Materials research and development for the spallation neutron source mercury target. J. Nucl. Mater. 2003, 318, 14-25. [CrossRef]

81. Mansur, L.K.; Gabriel, T.A.; Haines, J.R.; Lousteau, D.C. R\&D for the Spallation Neutron Source mercury target. J. Nucl. Mater. 2001, 296, 1-16.

82. Montanari, R.; Filacchioni, G.; Iacovone, B.; Plini, P.; Riccardi, B. High temperature indentation tests on fusion reactor candidate materials. J. Nucl. Mater. 2007, 367-370, 648-652. [CrossRef] 
83. Zinkle, S.J.; Ghoniem, N.M. Operating temperature windows for fusion reactor structural materials. Fusion Eng. Des. 2000, 51-52, 55-71. [CrossRef]

84. Van der Schaaf, B.; Gelles, D.S.; Jitsukawak, S.; Kimura, A.; Klueh, R.L.; Moslang, A.; Odette, G.R. Progress and critical issues of reduced activation ferritic/martensitic steel development. J. Nucl. Mater. 2000, 283-287, 52-59. [CrossRef]

85. Hishinuma, H.; Kohyama, A.; Klueh, R.L.; Gelles, D.S.; Dietz, W.; Ehrlich, K. Current status and future R\&D for reduced-activation ferritic/martensitic steels. J. Nucl. Mater. 1998, 258-263, 193-204.

86. Kittel, J.H.; Frost, B.R.T.; Mustelier, J.P.; Bagley, K.Q.; Crittenden, G.C.; Van Dievoet, J. History of fast reactor fuel development. J. Nucl. Mater. 1993, 204, 1-13. [CrossRef]

87. Zinkle, S.J. Fusion materials science and technology research opportunities nowand during the ITER era. Fusion Eng. Des. 2014, 89, 1579-1585. [CrossRef]

88. Zinkle, S.J. Radiation-induced effects on microstructure. In Comprehensive Nuclear Materials; Konings, R.J.M., Ed.; Elsevier: Amsterdam, The Netherlands, 2012; Volume 1, pp. 65-98.

89. Kajita, S.; Sakaguchi, W.; Ohno, N.; Yoshida, N.; Saeki, T. Formation process of tungsten nanostructure by the exposure to helium plasma under fusion relevant plasma conditions. Nucl. Fusion 2009, 49, 095005. [CrossRef]

90. Zenobia, S.; Garrison, L.M.; Kulcinski, G.L. The response of polycrystalline tungsten to $30 \mathrm{keV}$ helium ion implantation at normal incidence and high temperatures. J. Nucl. Mater. 2012, 425, 83-92. [CrossRef]

91. Tanabe, T. Tritium issues to be solved for establishment of a fusion reactor. Fusion Eng. Des. 2012, 87, 722-777. [CrossRef]

92. Zinkle, S.J. Fusion materials science: Overview of challenges and recent progress. Phys. Plasmas 2005, 12, 5. [CrossRef]

93. Dai, Y.; Odette, G.R.; Yamamoto, T. The effects of helium in irradiated structuralalloys. In Comprehensive Nuclear Materials; Konings, R.J.M., Ed.; Elsevier: Amsterdam, The Netherlands, 2012; Volume 1, pp. 141-193.

94. Yamamoto, T.; Odette, G.R.; Kishimoto, H.; Rensman, J.-W.; Miao, P. On the effects of irradiation and helium on the yield stress changes and hardening and non-hardening embrittlement of $8 \mathrm{Cr}$ tempered martensitic steels: Compilation and analysis of existing data. J. Nucl. Mater. 2006, 356, 27-49. [CrossRef]

95. Kurtz, R.J.; Alamo, A.; Lucon, E.; Huang, Q.; Jitsukawa, S.; Kimura, A.; Klueh, R.L.; Odette, G.R.; Petersen, C.; Sokolov, M.A.; et al. Recent progress toward development of reduced activation ferritic/martensitic steelsfor fusion structural applications. J. Nucl. Mater. 2009, 386-388, 411-417.

96. Blanchard, J.P.; Martin, C.J.; Tillack, M.S.; Wang, X.R. Ratcheting Models for Fusion Component Design. Fusion Sci. Technol. 2011, 60, 313-317.

97. Majumdar, S.; Kalinin, G. ITER structural design criteria and their extension to advanced fusion reactor blankets. J. Nucl. Mater. 2000, 283-287, 1424-1428. [CrossRef]

98. Bloom, E.E.; Busby, J.T.; Duty, C.E.; Maziasz, P.J.; McGreevy, T.E.; Nelson, B.E.; et al. Critical questions in materials science and engineering for successful development of fusion power. J. Nucl. Mater. 2007, 367-370, 1-10. [CrossRef]

99. Karditsas, P.J. Design issues and implications for structural integrity of fusion power plant components. Fusion Eng. Des. 2009, 84, 2104-2108. [CrossRef]

100. Kasahara, N.; Satoh, K.; Tsukimori, K.; Kawasaki, N. Proposals of guidelines for high temperature structural design of fast reactor vessels. In Proccedings of the ASME Pressure Vessels \& Piping Conference, New York, NY, USA, 18-22 July 2010.

101. Berton, M.N.; Ancelet, O.; Gelineau, O.; Sperandio, M. Presentation of RCC-MRcode 2007 for high temperature reactor and ITER projects: Improvement of the creep fatigue rules. In Proceedings of the ASME Pressure Vessels and Piping Conference, New York, NY, USA, 26-30 July 2009; pp. 567-572.

102. Zinkle, S.J.; Möslang, A.; Muroga, T.; Tanigawa, H. Multimodal options for materials research to advance the basis for fusion energy in the ITER era. Nucl. Fusion 2013, 53, 104024. [CrossRef]

103. Moreau, R.; Brechet, Y.; Maniguet, L. Eurofer corrosion by the flow of the eutectic alloy Pb-Li in the presence of a strong magnetic field. Fusion Eng. Des. 2011, 86, 106-120. [CrossRef]

104. Zinkle, S.J. Challenges in developing materials for fusion technology-Past, present, and future. Fusion Sci. Technol. 2013, 64, 65-75. [CrossRef] 
105. Ihli, T.; Basu, T.K.; Giancarli, L.M.; Konishi, S.; Malang, S.; Najmabadi, F.; Nishio, S.; Raffray, A.R.; Rao, C.V.S.; Sagara, A.; et al. Review of blanket designs for advanced fusion reactors. Fusion Eng. Des. 2008, 83, 912-919. [CrossRef]

106. Giancarli, L.; Chuyanov, V.; Abdou, M.A.; Akiba, M.; Hong, B.G.; Laesser, R.; Pan, C.; Strebkov, H.; the TBWG. Breeding blanket modules testing in ITER: An international program on the way to DEMO. Fusion Eng. Des. 2006, 81, 393-405. [CrossRef]

107. Tillack, M.S.; Turnbull, A.D.; Waganer, L.M.; Malang, S.; Steiner, D.; Sharpe, J.P.; Cadwallader, L.C.; El-Guebaly, L.; Raffray, A.R.; Najmabadi, F.; et al. An evaluation of fusion energy R\&D gaps using technology readiness levels. Fusion Sci. Technol. 2009, 56, 949-956.

108. Stambaugh, R.D.; Chan, V.S.; Garofalo, A.M.; Sawan, M.; Humphreys, D.A.; Lao, L.L.; Leuer, J.A.; Petrie, T.W.; Prater, R.; Snyder, P.B.; et al. Fusion nuclear science facility candidates. Fusion Sci. Technol. 2011, 59, $279-307$. [CrossRef]

109. Burn, J. Fusion Materials Semiannual Progress Report for the Period Ending June 30, 1998; Oak Ridge National Lab.: Oak Ridge, TN, USA, 1998.

110. Zinkle, S.J.; Eatherly, W.S. Effect of Heat Treatments on the Tensile and Electrical Properties of High-Strength, High-Conductivity Copper Alloys; Fusion Materials Semiannual Progress Report for Period Ending, June 30, 1997, DOE/ER-0313/22; Oak Ridge National Lab: Oak Ridge, TN, USA, 1997.

111. Harkness, J.C.; Spiegelberg, W.D.; Cribb, W.R. Properties and Selection: Nonferrous Alloys and Special-Purpose Materials, Metals Handbook, 10th ed.; ASM International: Materials Park, OH, USA, 1990; Volume 2, p. 403.

112. Murray, H.A. Development of a welding procedure for high conductivity, copper-beryllium alloy C17510. In Proceedings of the 14th IEEE/NPSS Symposium on Fusion Engineering, San Diego, CA, USA, 30 Sepember-3 October 1991; Volume 1, pp. 272-275.

113. Dieter, G.E. Mechanical Metallurgy, 2nd ed.; McGraw-Hill: New York, NY, USA, 1976.

114. Haasen, P. Physical Metallurgy; Cambridge Univ. Press: New York, NY, USA, 1978.

115. Spitznagel, J.A.; Doyle, N.J.; Choyke, W.J.; Greggi, J.G.; McGruer, J.N.; Davis, J.W. Ion irradiation effects on high strength, high conductivity copper alloys. Nucl. Instrum. Meth. B 1986, 16, 279-287. [CrossRef]

116. Rioja, R.J.; Laughlin, D.E. The sequence of precipitation in Cu-2w/o Be alloys. Acta Metall. 1980, 28, 1301-1313. [CrossRef]

117. Monzen, R.; Seo, T.; Sakai, T.; Watanabe, C. Precipitation Processes in a Cu-0.9 mass\% Be Single Crystal. Mater. Trans. 2006, 47, 2925-2934. [CrossRef]

118. Xie, G.; Wang, Q.; Mi, X.; Xiong, B.; Peng, L. The precipitation behavior and strengthening of a Cu-2.0 wt $\%$ Be alloy. Mater. Sci. Eng. A 2012, 558, 326-330.

119. Watanabe, C.; Monzen, R. Precipitation process in a Cu-Ni-Be alloy. Diffus. Defect Data B Solid State Phenom. 2011, 172-174, 432-436. [CrossRef]

120. Fabritsiev, S.; Pokrovsky, A.S.; Zinkle, S.J.; Rowcliffe, A.; Edwards, D.J.; Garner, F.A. The effect of neutron spectrum on the mechanical and physical properties of pure copper and copper alloys. J. Nucl. Mater. 1996, 233-237, 526-533. [CrossRef]

121. Fabritsiev, S.A.; Pokrovsky, A.S. The effect of neutron irradiation on the electrical resistivity of high-strength copper alloys. J. Nucl. Mater. 1997, 249, 239-249. [CrossRef]

122. Edwards, D.J. Temperature and Strain Rata Effects in High Strength High Conductivity Copper Alloys Tested in Air; Fusion Materials Semiannual Progress Report for Period Ending, December 31, 1997, DOE/ER-0313/23; Oak Ridge National Lab.: Oak Ridge, TN, USA, 1997; p. 213.

123. Slattery, K. Personal communication; McDonnell Douglas Corp.: St. Louis, MO, USA, 1997.

124. Lucas, G.E. Review of small specimen test techniques for irradiation testing. Metall. Trans. A 1990, $21,1105$. [CrossRef]

125. Sun, Z.; Laitern, C.; Vincent, A. Dynamic embrittlement at intermediate temperature in a Cu-Ni-Si alloy. Mater. Sci. Eng. A 2008, 477, 145-152. [CrossRef]

126. Laporte, V. Mortensen, Intermediate temperature embrittlement of copper alloys. Int. Mater. Rev. 2009, 54, 94-116. [CrossRef]

127. Fenici, P.; Boerman, D.J.; Tartaglia, G.P.; Elen, J.D. Effect of fast-neutron irradiation on tensile properties of precipitation-hardened Cu-Cr-Zr alloy. J. Nucl. Mater. 1994, 212-215, 399-403. [CrossRef]

128. Fabritsiev, S.A.; Pokrovsky, A.S.; Zinkle, S.J.; Edwards, D.J. Low-temperature radiation embrittlement of copper alloys. J. Nucl. Mater. 1996, 233-237, 513-518. [CrossRef] 
129. Fabritsiev, S.A.; Pokrovsky, A.S.; Edwards, D.J.; Zinkle, S.J.; Rowcliffe, A.F. Effect of high-dose neutron irradiation on the mechanical properties and structure of copper alloys and $\mathrm{Cu} / \mathrm{SS}$ joints for ITER applications. J. Nucl. Mater. 2000, 283-287, 523-527. [CrossRef]

130. Rowcliffe, A.F.; Mansur, L.K.; Hoelzer, D.T.; Nanstad, R.K. Perspectives on radiation effects in nickel-base alloys for applications in advanced reactors. J. Nucl. Mater. 2009, 392, 341-352. [CrossRef]

131. Boothby, R.M. Radiation Effects in Nickel-Based Alloys. In Comprehensive Nuclear Materials; Konings, R.J.M., Ed.; Elsevier: Amsterdam, The Netherlands, 2012; Volume 4, pp. 123-150.

132. Zinkle, S.J. Evaluation of high strength, high conductivity CuNiBe alloys for fusion energy applications. J. Nucl. Mater. 2014, 449, 277-289. [CrossRef]

133. Barbato, F.; Scarpellini, D.; Malizia, A.; Gaudio, P.; Richetta, P.; Antpnelli, L. X-ray High-Resolution Spectroscopy for Laser-Produced Plasma. Phys. Procedia 2015, 62, 84-91. [CrossRef]

134. Mattoccia, A.; Bernardone, E.; Digiamberardino, L.; Gaudio, P.; Malizia, A.; Orsini, A. Morphological and structural investigation of $(\mathrm{Zn}, \mathrm{Al})$ layered double hydroxides $(\mathrm{LDH})$ nanoplatelets synthesized on aluminum-coated substrates [Studio morfologico di nanostrutture di layered double hydroxides (LDH) depositate su film sottili di alluminio]. Metall. Ital. 2015, 107, 15-22.

135. Kulite Semiconductor Products, Inc., Leonia, NJ, USA. Available online: www.kulite.com/docs/products/ XCE-093.pdf (accessed on 1 March 2016).

136. Benedetti, M.; Gaudio, P.; Lupelli, I.; Malizia, A.; Porfiri, M. T.; Richetta, M. Scaled experiment for Loss of Vacuum Accidents in nuclear fusion devices: Experimental methodology for fluid-dynamics analysis in STARDUST facility. Available online: http://www.wseas.us/e-library/conferences/2011/ Corfu/CUTAFLUP/CUTAFLUP-24.pdf (accessed on 19 July 2016).

137. Bellecci, C.; Gaudio, P.; Lupelli, I.; Malizia, A.; Porfiri, M.T.; Quaranta, R. Loss of vacuum accident (LOVA): Comparison of computational fluid dynamics (CFD) flow velocities against experimental data for the model validation. Fusion Eng. Des. 2011, 86, 330-340. [CrossRef]

138. Bellecci, C.; Gaudio, P.; Lupelli, I.; Malizia, A.; Porfiri, M.T.; Quaranta, R.; Richetta, M. STARDUST experimental campaign and numerical simulations: Influence of obstacles and temperature on dust resuspension in a vacuum vessel under LOVA. Nucl. Fusion 2011, 51, 053017. [CrossRef]

139. Gaudio, P.; Malizia, A.; Lupelli, I. Experimental and numerical analysis of dust resuspension for supporting chemical and radiological risk assessment in a nuclear fusion device. In Proceedings of the International Conference on Mathematical Models for Engineering Science (MMES' 10), Puerto De La Cruz, Spain, 30 November-2 December 2010; pp. 134-147.

140. Bellecci, C.; Gaudio, P.; Lupelli, I.; Malizia, A.; Porfiri, M.T.; Quaranta, R.; Richetta, M. Exerimental Mapping of Velocity Flow Field in Case of L.O.V.A. inside STARDUST facility. In Proceedings of the 37th EPS Conference on Plasma Physics, Dublin, Ireland, 21-25 June 2010; pp. 703-706.

141. Bellecci, C.; Gaudio, P.; Lupelli, I.; Malizia, A.; Porfiri, M.T.; Quaranta, R.; Richetta, M. Characterization of divertor influence in case of LOVA: CFD analysis of STARDUST experimental facility. In Proceedings of the 36th EPS Conference on Plasma Physics, Sofia, Bulgaria, 29 June-3 July 2009.

142. Ciparisse, J.-F.; Malizia, A.; Poggi, L.A.; Cenciarelli, O.; Gelfusa, M.; Carestia, M.C.; Di Giovanni, D.; Mancinelli, S.; Palombi, L.; Bellecci, C.; et al. Numerical Simulations as Tool to Predict Chemical and Radiological Hazardous Diffusion in Case of Nonconventional Events. Model. Simul. Eng. 2016, 2016, 1-11. [CrossRef]

143. Malizia, A.; Carestia, M.; Cafarelli, C.; Milanese, L.; Pagannone, S.; Pappalardo, A.; Pedemonte, M.; Latini, G.; Barlascini, O.; Fiorini, E.; et al. The free license codes as Decision Support System (DSS) for the emergency planning to simulate radioactive releases in case of accidents in the new generation energy plants. WSEAS Trans. Env. Dev. 2014, 10, 453-464.

144. Camplani, M.; Malizia, A.; Gelfusa, M.; Barbato, F.; Antonelli, L.; Poggi, L.A.; Ciparisse, J.-F.; Salgado, L.; Richetta, M.; Gaudio, P. Image computing techniques to extrapolate data for dust tracking in case of an experimental accident simulation in a nuclear fusion plant. Rev. Sci. Instrum. 2016, 87, 013504. [CrossRef] [PubMed]

145. Gaudio, P.; Maliza, A.; Camplani, M.; Barbato, F.; Antonelli, L.; Gelfusa, M.; Del Vecchio, M.; Salgado, L.; Bellecci, C.; Richetta, M. Shadowgraph technique applied to STARDUST facility for dust tracking: First results. In Proceedings of 3rd International Conference Frontiers in Diagnostic Technologies (ICFDT3 2013), Rome, Italy, 25-27 November 2013; pp. 97-101. 
146. Ciparisse, J.-F.; Malizia, A.; Poggi, L.A.; Gelfusa, M.; Murari, A.; Mancini, A.; Gaudio, P. First 3D numerical simulations validated with experimental measurements during a LOVA reproduction inside the new facility STARDUST-Upgrade. Fusion Eng. Des. 2015, 101, 204-208. [CrossRef]

147. Lupelli, I.; Gaudio, P.; Richetta, M.; Gelfusa, M.; Malizia, A.; Belluzzo, I.; Richetta, M. Numerical study of air jet flow field during a loss of vacuum. Fusion Eng. Des. 2014, 89, 2048-2052. [CrossRef]

148. Benedetti, M.; Gaudio, P.; Lupelli, I.; Malizia, A.; Porfiri, M.T.; Richetta, M. Large Eddy simulation of loss of Vacuum accident in STARDUST facility. Fusion Eng. Des. 2013, 88, 2665-2668. [CrossRef]

149. Malizia, A.; Gelfusa, M.; Francia, G.; Boccitto, M.; Del Vecchio, M.; Di Giovanni, D.; Richetta, M.; Bellecci, C.; Gaudio, P. Design of a new experimental facility to reproduce LOVA and LOCA consequences on dust resuspension. Fusion Eng. Des. 2015, 98-99, 2191-2195. [CrossRef]

(C) 2016 by the authors; licensee MDPI, Basel, Switzerland. This article is an open access article distributed under the terms and conditions of the Creative Commons Attribution (CC-BY) license (http://creativecommons.org/licenses/by/4.0/). 